Prepared for the U.S. Department of Energy

under Contract DE-AC05-76RL01830

\title{
China's Building Energy Use: A Long-Term Perspective based on a Detailed Assessment
}
J Eom
P Kyle
LE Clark
PL Patel
SH Kim

January 2012

Pacific Northwest

NATIONAL LABORATORY

Proudly Operated by Battelle Since 1965 


\title{
DISCLAIMER
}

This report was prepared as an account of work sponsored by an agency of the United States Government. Neither the United States Government nor any agency thereof, nor Battelle Memorial Institute, nor any of their employees, makes any warranty, express or implied, or assumes any legal liability or responsibility for the accuracy, completeness, or usefulness of any information, apparatus, product, or process disclosed, or represents that its use would not infringe privately owned rights. Reference herein to any specific commercial product, process, or service by trade name, trademark, manufacturer, or otherwise does not necessarily constitute or imply its endorsement, recommendation, or favoring by the United States Government or any agency thereof, or Battelle Memorial Institute. The views and opinions of authors expressed herein do not necessarily state or reflect those of the United States Government or any agency thereof.

\author{
PACIFIC NORTHWEST NATIONAL LABORATORY \\ operated by \\ BATTELLE \\ for the \\ UNITED STATES DEPARTMENT OF ENERGY \\ under Contract DE-AC05-76RL01830
}

Printed in the United States of America
Available to DOE and DOE contractors from the Office of Scientific and Technical Information,
P.O. Box 62, Oak Ridge, TN 37831-0062;
ph: (865) 576-8401
fax: $(865) 576-5728$
email: reports@adonis.osti.gov

\footnotetext{
Available to the public from the National Technical Information Service, U.S. Department of Commerce, 5285 Port Royal Rd., Springfield, VA 22161 ph: (800) 553-6847 fax: $(703) 605-6900$ email: orders@ntis.fedworld.gov online ordering: http://www.ntis.gov/ordering.htm
}

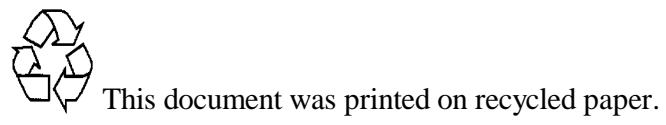




\title{
China's Building Energy Use: A Long-Term Perspective based on a Detailed Assessment
}

\author{
J Eom GP Kyle \\ LE Clarke PL Patel \\ SH Kim
}

January 2012

Prepared for the U.S. Department of Energy under Contract DE-AC05-76RL01830

Pacific Northwest National Laboratory

Richland, Washington 99352 


\begin{abstract}
We present here a detailed, service-based model of China's building energy use, nested in the GCAM (Global Change Assessment Model) integrated assessment framework. Using the model, we explore longterm pathways of China's building energy use and identify opportunities of reducing greenhouse gas emissions. The inclusion of a structural model of building energy demands within an integrated assessment framework represents a major methodological advance. It allows for a structural understanding of the drivers of building energy consumption while simultaneously considering the other human and natural system interactions that influence changes in the global energy system and climate. We also explore a range of different scenarios to gain insights into how China's building sector might evolve and what the implications might be for improved building energy technology and carbon policies. The analysis suggests that China's building energy growth will not wane anytime soon, although technology improvement will put downward pressure on this growth. Also, regardless of the scenarios represented, the growth will involve the continued, rapid electrification of the buildings sector throughout the century, and this transition will be accelerated by the implementation of carbon policy.
\end{abstract}

Keywords: China buildings; Building energy modeling; Scenario Analysis; Integrated assessment model; Electrification 


\section{Contents}

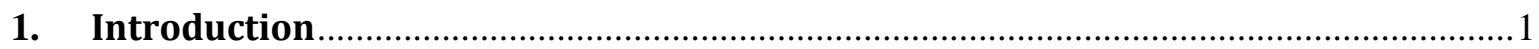

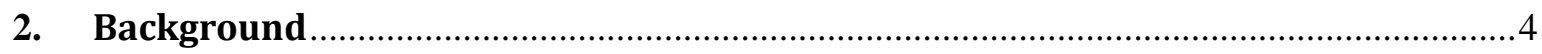

2.1 Current Building Energy Use in China ....................................................................

2.2 Projections of Building Energy Consumption in China...............................................6

2.3 GCAM Integrated Assessment Model Core Assumptions for Analysis .......................7

2.4 Core Assumptions of the GCAM Reference Scenario ................................................

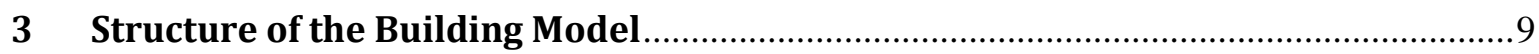

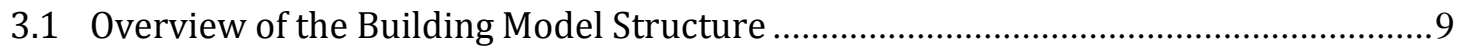

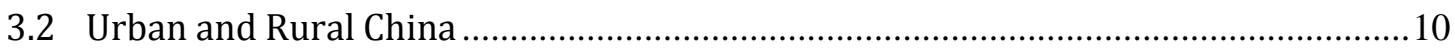

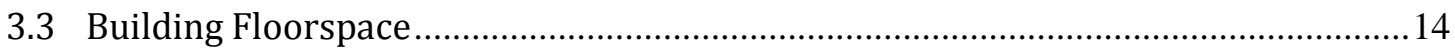

3.4 Representing Building Energy Service Demands....................................................... 18

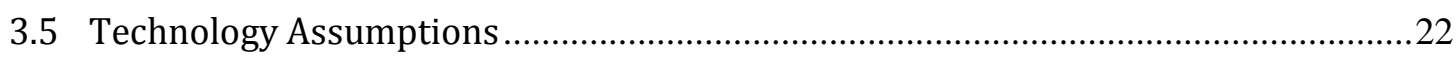

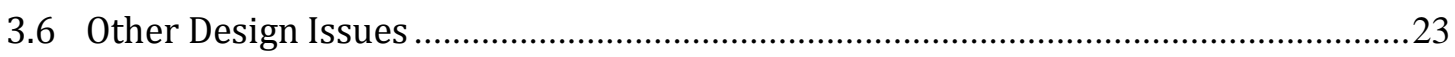

3.6.1 Varying Service and Fuel Preferences..........................................................2 23

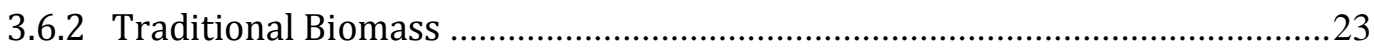

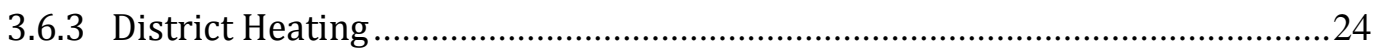

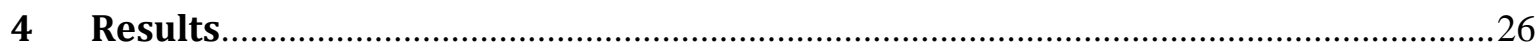

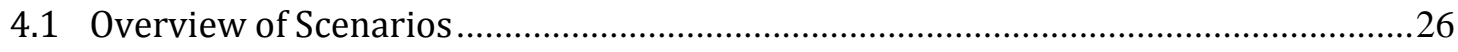

4.2 Building Energy Consumption in the Scenarios ....................................................28

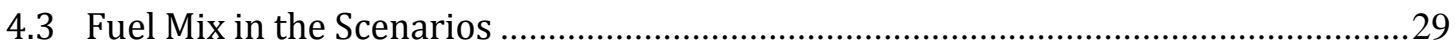

4.4 Evolution of Building Service Demands and Fuel Uses in the Scenarios ....................33

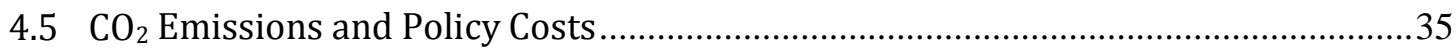

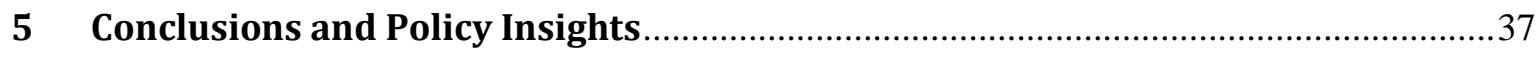

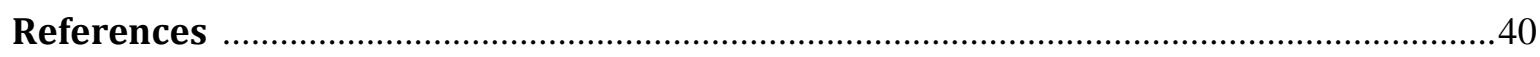

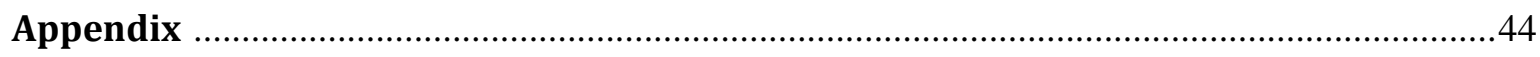




\section{Introduction}

It is widely recognized that any attempt to address climate change will ultimately have to include China. The Chinese economy has grown at a remarkable rate of 9-10\% per year since 1990s, and expectations are that it will continue to grow rapidly. Energy consumption and associated $\mathrm{CO}_{2}$ emissions have increased dramatically as a result of this growth. China consumed almost three times as much energy in 2006 as it did in 1990. China is now the second largest energy consumer after the U.S. China is now the biggest $\mathrm{CO}_{2}$ emitter in the world [1-2]. ${ }^{1}$

Buildings are an important contributor to China's energy consumption and $\mathrm{CO}_{2}$ emissions. Measures to address energy consumption and associated emissions from the buildings sector will therefore be an important part of any strategy to reduce China's $\mathrm{CO}_{2}$ emissions. In 2007, China's buildings sector consumed $31 \%$ of China's total final energy [1]. China is also the second largest building energy user in the world, ranked $1^{\text {st }}$ in residential energy consumption and $3^{\text {rd }}$ in commercial energy consumption [1]. In 2005, China's buildings sector emitted roughly 0.4 Gton of $\mathrm{CO}_{2}$ for primary fuel uses; indirect electricity emissions included, the emissions amounted to about $1.1 \mathrm{Gton}$ of $\mathrm{CO}_{2}$, or $18 \%$ of China's total fossil and industrial $\mathrm{CO}_{2}$ emissions. ${ }^{2}$ As China continues its socioeconomic transformation, energy consumption and associated emissions from the buildings sector will undoubtedly increase.

The topic of this paper is this evolution of the Chinese buildings sector through mid-century and beyond, and the potential influence of socioeconomic factors as well as climate and energy policies on this evolution. Understanding the potential nature and magnitude of this evolution is challenging. Indeed, there is indeed tremendous variation even in short-term projections of building energy consumption in China (see, for example, $\mathrm{Li}$ [3]). There are many factors that contribute to this uncertainty, including the rate of population and economic growth, the rate of transformation in China from a rural to urban economy, the increase in floorspace associated with economic growth, the nature of the building services (e.g., air conditioning, plug loads) that Chinese will demand in the future, and the technologies that will be available to provide these services.

This paper explores the long-term evolution of China's building sector through the construction and application of a technologically detailed, service-based model of China's building sector nested in the

\footnotetext{
${ }^{1}$ There is some degree of recognition by the Chinese of their role in climate mitigition. As part of the 2009 Copenhagen Accord, China pledged to reduce its carbon intensity by $40-45 \%$ by 2020 relative to 2005 . China's economic planning department has decided to develop a so-called "Low-Carbon Economy", which would require various measures ranging from expanding non-fossil renewable energy capacities to promoting end-use energy efficiencies throughout the economy.

${ }^{2}$ Throughout this study, we calculated estimates of $\mathrm{CO}_{2}$ emissions by multiplying the amount of fuel consumed with its associated carbon emissions coefficient. This largely applies to electricity, for which the average $\mathrm{CO}_{2}$ per $\mathrm{kWh}$ of electricity is applied.
} 
long-term, global, integrated-assessment framework, the Global Change Assessment Model (GCAM). The China buildings model builds on previous work on the U.S. buildings sector in GCAM [4]. However, the construction of a model for China-and for a developing country more generally-provides a number of unique challenges associated with rapid economic development and associated shifts from rural to urban energy uses.

This paper makes two primary contributions to our understanding of buildings in China. The first contribution is methodological: the inclusion of a fully intergrated China building energy model within an integrated assessment framework. Integrated assessment models are one of the primary tool for exploring the long-term interactions between human and earth systems and the possible implications of long-term policy structures and options for greenhouse gas mitigation (see, for example, Clarke et al. [5-6]). These models have historically focused far more heavily on the supply and conversion side of the energy system than the demand side. The inclusion of the buildings module within an integrated assessment framework, as opposed to a stand-alone version, provides the advantage of integration. It allows for consideration of how the Chinese buildings sector might interact with the remainder of both the Chinese and global energy systems, particularly in the context of climate mitigation. Moreover, the integrated assessment modeling allows for a comprehensive analysis of the effects of policy instruments, such as price on carbones, tradable emissions permits, or technology focused policies such as buildings standards.

The second contribution of this paper is to enhance our understanding of the possible evolution of China's building sector, the interaction with climate policies, and the potential implications over the long term of building energy efficiency measures. The process of constructing any model forces the model developer to grapple with and understand the key forces that shape its behavior, and this process provides many insights in and of itself. Using the model to produce scenarios then provides additional understanding about how these forces interact. In particular, we focused our efforts in constructing the model on five key issues: (1) the rate of urbanization in China and its relationship to overall economic growth, (2) the demand for building floorspace associated with this growth and urbanization, (3) the associated demand for building energy services, (4) the technologies that might be available and deployed in the future, and (5) urban-to-rural differences in energy services and fuels. The scenarios explored in the model then focus on the implications of economic growth rates, the degree of technological change, and the nature of climate policy.

In general, the research confirms intuition. The exercise suggests a dramatic expansion in building energy consumption in China, associated with rapid economic growth and urbanization of the Chinese economy. This holds for all the scenarios in this paper. Within this larger context, the model also suggests that the Chinese buildings sector will undergo rapid electrification, and a climate policy would 
lead to more rapid electrification, reducing its dependence on traditional biomass, coal, and oil. The model also suggest that while rural income growth would gradually phase out the use of traditional biomass, a climate policy may result in a prolonged use of traditional biomass. Looking forward, the newly constructed model offers a means to explore not only the interaction between the Chinese buildings sector and efforts to mitigate climate change, but also the impact of a changing climate on building energy consumption in any part of the world.

The remainder of the paper is structured as follows. Section 2 provides background. It describes the characteristics of building energy use in China in comparison with developed countries' historical building energy use, and it briefly introduces the GCAM integrated assessment model. Section 3 details the structure of the building energy model and discusses a variety of methodolgical issues associated with modeling buildings in a rapidly-growing economy like China's. Section 4 discusses the results emerging from the scenarios explored using the model. Concluding remarks are presented in Section 5. 


\section{Background}

\subsection{Current Building Energy Use in China ${ }^{3}$}

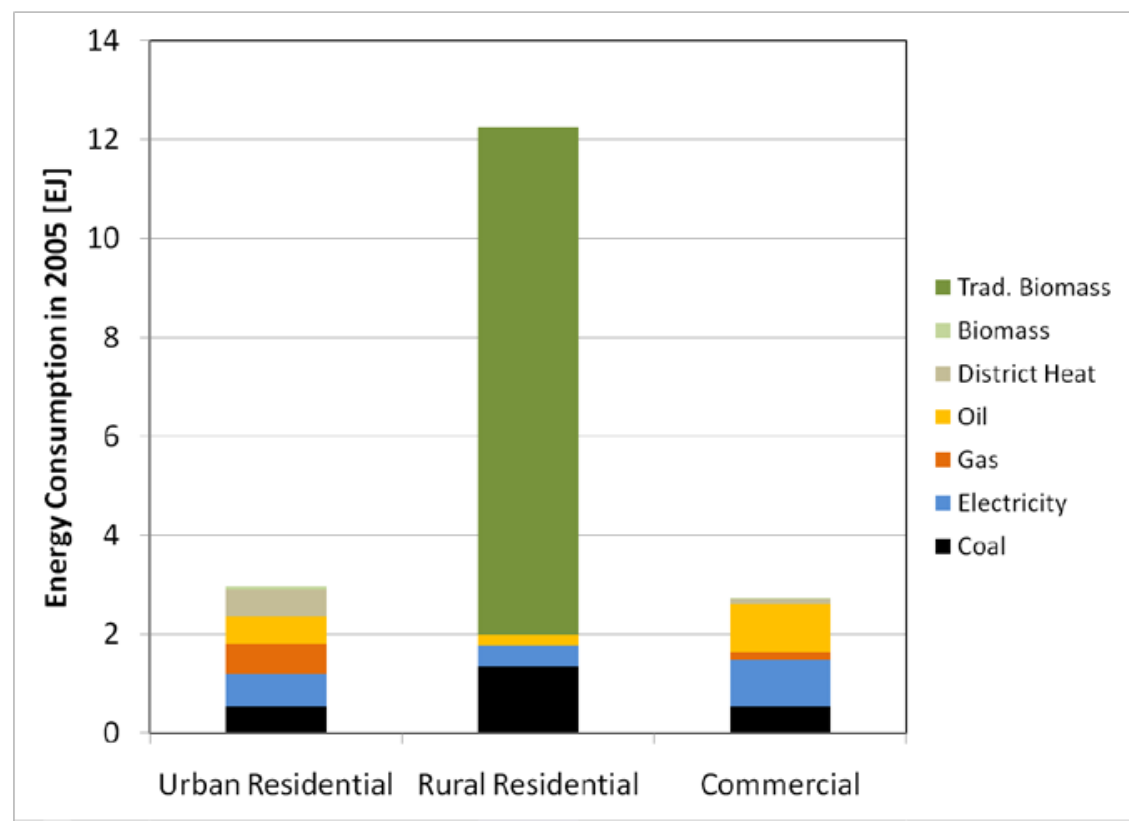

Figure 1: China's building energy consumption in 2005

The rural population plays an outsized role in China's building sector today. In 2005, rural energy consumption accounted for roughly two-thirds of total building final energy consumption (Figure 1). Although rural per capita income was about three times smaller than urban per capita income, rural percapita final energy consumption was more than three times larger than urban per-capita energy consumption in 2005 [7]. High final energy demand in rural buildings results from rural China's very intensive use of traditional biomass. Traditional biomass is highly inefficient: conversion efficiencies in developing countries range only between $5 \%$ and $20 \%$ [8]. Traditional biomass is widely used for

\footnotetext{
${ }^{3}$ Because of reliability and consistency problems with the sectoral energy breakdown provided by China's National Bureau of Statistics, as pointed out by Sinton [9], we instead used IEA's energy balances to characterize China's residential and commercial building energy consumption in $2005[1]^{3}$ and used the China Energy Databook to split the residential energy consumption into urban and rural uses [2]. Regarding service-level energy consumption, due to the absence of comprehensive national energy consumption survey, we have applied reasoned judgments based on several detailed energy use analyses and local surveys [10-13].
} 
cooking, space heating, and water heating in rural areas (Figure 2) [10,12]. ${ }^{4}$ The resource may continue to be a major part of the rural energy mix at least in the short term.

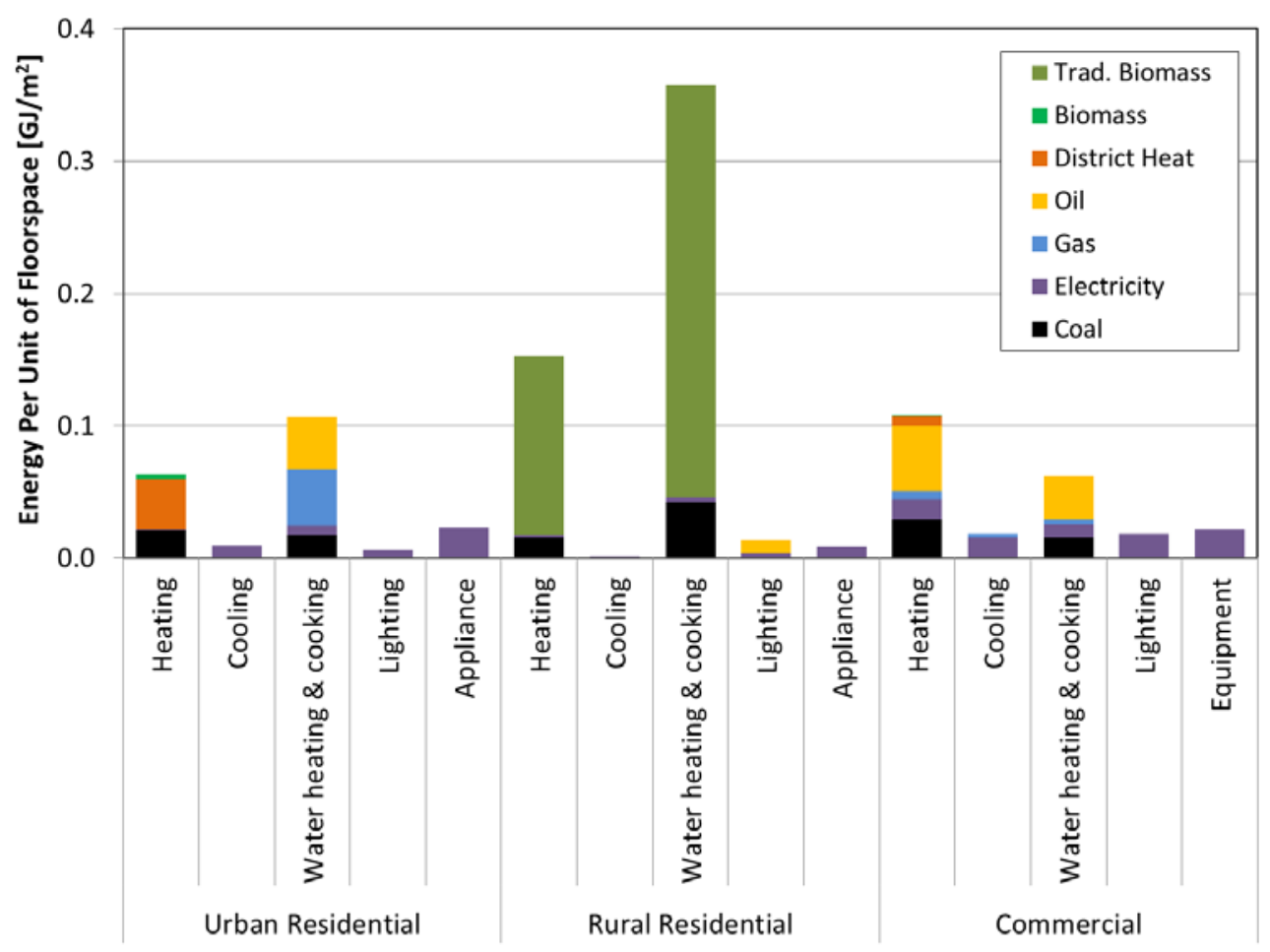

Figure 2: China's building energy use density by service and fuel in 2005

Another prominent feature of the Chinese buildings sector is the sizeable penetration of district heat systems in urban areas, particularly in the cold north-east region. In 2005, district heat represented $18 \%$ of total energy used by urban residential buildings and $3 \%$ of total energy used by commercial buildings across the country (Figure 2). With the government's push for district heat and power cogeneration, combined with the proposed national heat price reform, analyses have projected that heated residential floorspace will more than double between 2004 and 2024 [14].

Coal is still widely used in the Chinese buildings, mostly for heating, water heating, and cooking. This is true not just in rural residential buildings, but also in urban residential buildings and commercial buildings. Gas, which includes both coal gas and natural gas, is used for urban water heating and cooking and for commercial heating, cooling, water heating, and cooking. Oil is still used for commercial heating, water heating, and cooking and urban water heating and cooking. It is used, in the form of kerosene, for

\footnotetext{
${ }^{4}$ Residential building energy use by service and fuel is based on the detailed residential end-use analyses conducted by Tonooka et al. [12] and Hu and Jiang [17]. Commercial building energy use is based on LBNL's estimates [11], combined with our reasoned judgment. We made sure that, for urban, rural, and commercial buildings, total consumption of each fuel across different services equal IEA's energy balance in 2005.
} 
lighting in rural areas. The penetration of electricity is still small and concentrated mostly in urban and commercial building services. Taken together, heating, water heating, and cooking accounted for $81 \%$ of urban residential energy use and $96 \%$ of rural residential energy use in 2005; and heating, water heating, and cooking accounted for $74 \%$ of commercial building energy use in 2005.

\subsection{Projections of Building Energy Consumption in China}

There is good reason to believe that China's building sector will consume more energy, and potentially a lot more energy, in the future than it does today. China's residential and commercial buildings consumed $0.41 \mathrm{GJ} / \mathrm{m}^{2}$ and $0.25 \mathrm{GJ} / \mathrm{m}^{2}$ of final energy in 2005 , far less than $0.83 \mathrm{GJ} / \mathrm{m}^{2}$ and 0.70 $\mathrm{GJ} / \mathrm{m}^{2}$ in Germany, $0.79 \mathrm{GJ} / \mathrm{m}^{2}$ and $1.31 \mathrm{GJ} / \mathrm{m}^{2}$ in France, and $1.02 \mathrm{GJ} / \mathrm{m}^{2}$ and $2.72 \mathrm{GJ} / \mathrm{m}^{2}$ in the U.S. In terms of per capita energy consumption, the gap becomes even greater due to large difference in per capita building floorspace. In 2005, China's per capita residential and commercial building energy consumptions were 11.6 and 2.1 GJ, far less than 31.1 GJ and 13.7 GJ in Germany, 30.5 GJ and 18.4 GJ in France, and 77.6 GJ and 64.1 GJ in the U.S. $[2,15,16] .{ }^{5}$ It would be surprising if China did not close this gap over the coming decades based on continuing economic growth and urbanization. With increased growth will come a rising demand for comfort in terms of increasing building energy services per unit of floorspace, as well as the expansion of building floorspace.

Recent studies have offered vastly different near-term projections of China's building energy consumption [3]. IEA [18] projected that China's building energy would increase to 24 EJ by 2020 from $18 \mathrm{EJ}$ in 2005 in the reference case, ERI [19] projected $19 \mathrm{EJ}$ in 2020, and EIA [20] projected $10 \mathrm{EJ}$ in 2020. The projected share of electricity in buildings final energy use in 2020 was $17 \%$ [1], 26\% [19], and $37 \%[20]{ }^{6}$

Only a small number of studies have developed detailed, bottom-up models for the Chinese buildings sector. Both ERI [19] and Zhou et al. [10] have used the technically detailed accounting model, LEAP, to produce projections of future energy use. In the LEAP model, exogenously specified trajectories of floorspace, service saturation, and energy use density are combined to yield total building energy uses. ERI [19] used the LEAP model to eplore the implications of strengthening China's building efficiency policies. The study projected that compared to their ordinary effort scenario, the green growth scenario would require about $25 \%$ less building energy use in 2020; and the share of electrity consumption changes from $25 \%$ in the ordinary effort scenario to $30 \%$ in the green growth scenario. Zhou

\footnotetext{
${ }^{5}$ All numbers are taken from 2005 energy uses, except for U.S. commercial building energy use, which was surveyed in 2006.

${ }^{6}$ Values from ERI [19] and EIA [20] do not include traditional biomass uses. IEA's estimate is interpolated by the authors between its-provided 2015 projection and 2030 projection.
} 
et al.[10] developed a reference scenario in which China's building primary energy consumption would grow at about $2.5 \%$ per annum to 2020 , and total primary energy consumption by urban households would surpass that of rural households in 2012.

\subsection{GCAM Integrated Assessment Model Core Assumptions for Analysis}

The China building energy model that we will describe in the next section is nested in the Global Change Assessment Model (GCAM), ${ }^{7}$ formerly known as MiniCAM [21]. Implemented in the Objectoriented Energy, Climate, and Technology Systems framework (ObjECTS) [22], GCAM has been utilized extensively for scenario analyses and technology assessment studies [5,6,23]. GCAM is a dynamicrecursive model, which combines parial equilibrium economic models of the global energy system $[21,24]$ and global land use [25], with a combination of gas-cycle, climate, and ice-melt models, integrated in the Model for the Assessment of Greenhouse-Gas Induced Climate Change (MAGICC) [26].

GCAM represents global (or regional) supplies for energy and agricultural products across 14 different regions (including the China region) to meet individual regions' demands. Future demands in GCAM, along with the equilibrium prices of individual products, are linked to region-specific assumptions of population growth, labor participation rates, and labor productivity. Other important inputs include technology costs and efficiencies, fossil and other resources, and climate or other policies. The equilibrium prices of all markets are obtained by the model in 15-year time periods from 2005 (calibration year) to 2095. ${ }^{8}$ Greenhouse gas emissions are determined endogenously based on the resulting energy, agriculture, and land use systems. Greenhouse gas concentrations, radiative forcing, and global temperature change are determined using MAGICC. GCAM is not an intertemporal optimization model. In each period, decisions in the model are made on current prices.

Another distinctive feature of GCAM is the logit specification used to determine market shares of technologies, for example, in the choice of heating technologies [27]. The logit approach has a long history in discrete choice analysis [28-29]. The logit approach is designed to represent decision making among competing options when only some characteristics of the options can be observed. A key characteristic of this approach is that not all decision makers will choose the same single technology option simply because its observed price is lowest of all competing technologies; even higher-priced options may take market share. In other words, GCAM does not exhibit winner-take-all behavior.

\footnotetext{
${ }^{7}$ For this study, we employed GCAM 1.1 with SVN version of 3726.

${ }^{8}$ Note that newer versions of GCAM operate on a user-defined time step. The most common time step used in GCAM is now 5 years.
} 


\subsection{Core Assumptions of the GCAM Reference Scenario}

As a modeling framework, there is no single set of assumptions that defines GCAM scenarios. Assumptions can be structured for whatever future an analyst wishes to explore. Particularly important for the evolution of the Chinese buildings sector are the population and GDP assumptions used in a scenario. For this exercise, one set of population numbers and two sets of labor productivity growth rates, were used to develop GDP scenarios for China (Table 1). In these scenarios, China's population and labor participation peak around 2035 and 2020, respectively, and start to decline thereafter. We consider two labor productivity growth scenarios: a high growth scenario and a low growth scenario. Labor productivity growth is $15 \%$ slower in the low-growth scenario relative to the high-growth scenario.

Table 1: Population and GDP assumptions of the China region in GCAM

\begin{tabular}{|c|c|c|c|c|c|c|c|c|c|}
\hline & & 1990 & 2005 & 2020 & 2035 & 2050 & 2065 & 2080 & 2095 \\
\hline \multicolumn{2}{|l|}{ Population [million] } & 1223 & 1427 & 1556 & 1587 & 1535 & 1461 & 1387 & 1303 \\
\hline \multicolumn{2}{|c|}{ Labor participation rate [\%] } & 57.4 & 60.9 & 62.0 & 60.3 & 54.1 & 47.4 & 45.6 & 44.8 \\
\hline Labor productivity & High Growth & - & 8.3 & 7.0 & 5.0 & 4.5 & 3.9 & 3.2 & 2.6 \\
\hline growth rate $[\% / y r]$ & Low Growth & - & 8.3 & 6.0 & 4.3 & 3.8 & 3.3 & 2.7 & 2.2 \\
\hline GDP & High Growth & 516 & 2113 & 6490 & 13377 & 22333 & 33090 & 48745 & 65744 \\
\hline [2005 billion USD] & Low Growth & 516 & 2113 & 5581 & 10337 & 15751 & 21424 & 29264 & 37490 \\
\hline GDP per capita & High Growth & 422 & 1481 & 4171 & 8429 & 14549 & 22649 & 35144 & 50456 \\
\hline [2005 USD] & Low Growth & 422 & 1481 & 3587 & 6513 & 10261 & 14664 & 21098 & 28772 \\
\hline
\end{tabular}




\section{Structure of the Building Model}

\subsection{Overview of the Building Model Structure}

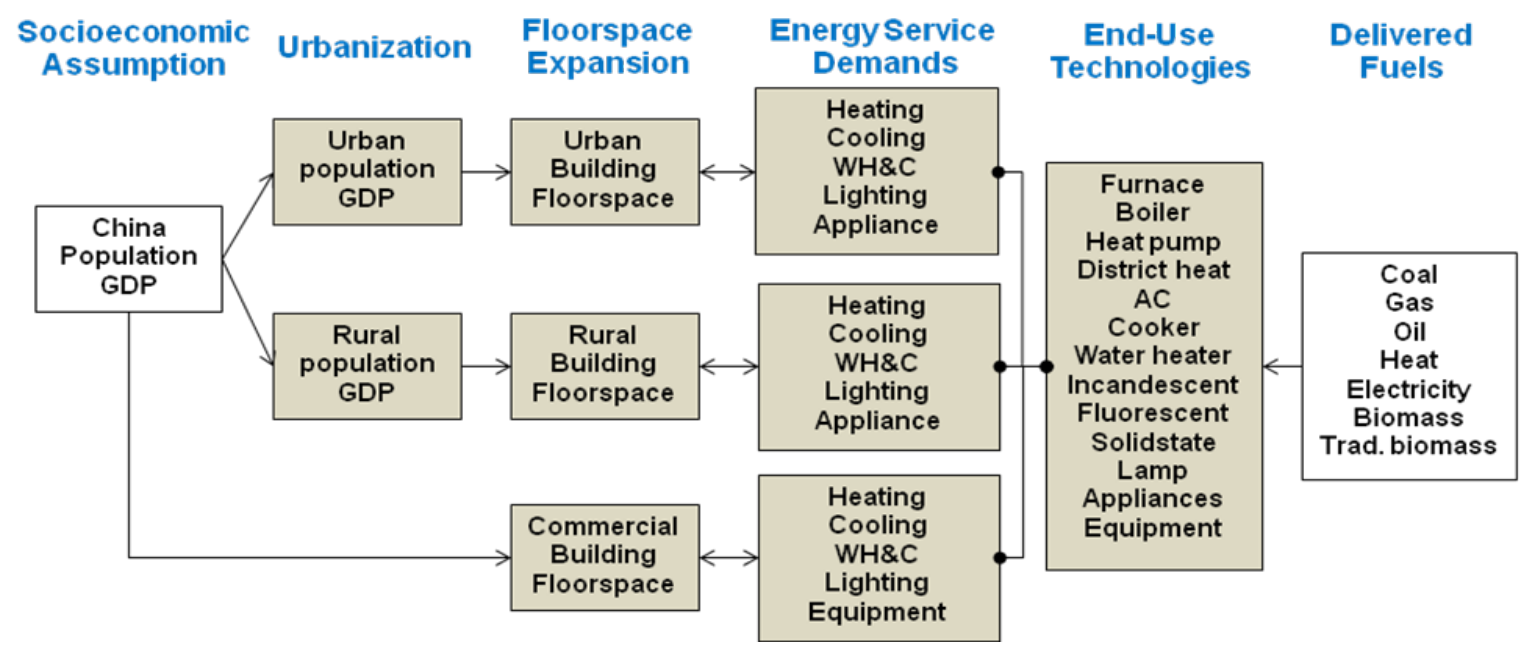

Figure 3: The structure of energy demand and supply in China buildings

The Chinese buildings sector in GCAM is split into three distinct building types: commercial buildings, urban residential buildings, and rural residential buildings (Figure 3). Each of these three building types is characterized by total floorspace and a range of physical attributes, such as thermal conductance of building envelope and floor-to-surface area ratio. Each of the three building types demands a set of building energy services (i.e., heating, cooling, water heating, cooking, lighting, appliances, and equipment). Building energy services are supplied by competing end-use technologies, each of which consumes one or more of marketed fuels (i.e., coal, gas, oil, heat, electricity, and biomass) as well as traditional biomass in some cases.

It is important to emphasize that because this model exists within a global, long-term integrated assessment framework, it must interact with the rest of the economy and energy system. There are two primary means for this interaction. First, population and GDP for China directly influence both the demand for floospace and the demand for services associated with that floorspace (the left side of Figure 3 ). Second, fuel prices influence the relative and absolute costs of supplying services with different enduse technologies (the right side of Figure 3 ). ${ }^{9}$ Note that fuel prices are not an exogenous input to GCAM.

\footnotetext{
${ }^{9}$ In this report, we do not consider the effect of long-term climate change on heating and cooling service demands. However, the model is flexible enough to utilize the changes in heating degree days (HDDs) and cooling degree
} 
They are endogenous to the model, reacting to assumptions about resource bases, climate and other policies, and technology, among other things.

The remainder of this section explores the construction of the model by considering five key forces, working from left to right in Figure 3. First, how might China's urban and rural populations and income change over time given GDP and population rates in China? Second, how will floorspace demand respond to changing GDP and population? Third, what services and in what quantities will these buildings demand? Fourth, what technologies might be available and deployed in the future? Fifth, and finally, how can we represent changes in urban and rural preferences for individual energy service demands and in fuel options both in the near-term and also over the long-term?

\subsection{Urban and Rural China}

Recall that GCAM begins with total population and GDP assumptions for China. However, these assumptions hide an important next level of detail about whether these people live in rural or urban environments and how wealthy the urban population is relative to the rural population. Information about rural and urban populations is important because urban and rural building characteristics and end-use patterns are very different. Hence, it is necessary to develop a reasonable representations and reasonable projections of the relationship between the proportion of the population in rural and urban households, on the one hand, and the relative wealth of these households on the other.

It is important to note that there are definitional issues associated with the assignation of populations as either urban or rural. Currently, four factors are known to determine the size of urban population: (i) the criteria for urban designation (i.e., administrative status, minimum population size, and occupational structure) (ii) the designated places' physical and administrative boundaries (iii) the household registration system (hukou) and (iv) the urban status of the unregistered population [30]. Thus, in practice, urban designation relates more to administrative status. Although the average urban household is more affluent than the average rural household, compared to the urban poor, the rural rich could demand more energy services and have better access to energy infrastructure than the urban poor. In other words, an urban and rural classification system is not the same as classification system that explicitly distinguishes modern and traditional uses of energy. It is also important to note that China's definitions of urban and rural, on which socioeconomic and energy consumption data is based, have changed several times over the last two decades [31].

days (CDDs) that can be calculated based on spatially-explicit climate simulation models. This climatic interaction will be addressed in future work. 
Unfortunately, there is no established theory to fall back on to formulate a mechanism to represent urbanization for use in GCAM. There have been few studies on determinants and magnitude of urbanization, largely because of the complexity of the issue. As a consequence, we lack a deep empirical understanding about the region-specific drivers of urbanization. What the literature has shown is that urban population growth is attributed to three different sources: natural increase in the urban population, reclassification of rural places to urban places, and rural-to-urban migration. Chan \& $\mathrm{Hu}$ [32] attributed nearly $60 \%$ of China's urban population increase occurred in 1990s to net rural-to-urban migration, $22 \%$ to urban reclassification, and $20 \%$ to urban natural increase. Zhang \& Song [33] also suggested that migration made dominant contributions to Chinese urban population growth between 1978-1999. Some studies have theorized that migration occurs in the process of shifting of labor from rural places with zero marginal labor productivity to growing urban industrial places with high marginal productivity [34-35] and that the migration decision is made to maximize expected net earnings from relocation [36]. However, these idealized models are not directly applicable for long-term projection of urbanization, unless spatially explicit movement of productive inputs and associated economic development are modeled at the regional level, which is beyond the scope of this study. The task becomes even more challenging when we also account for even more complicated issues of urban reclassification and natural growth.

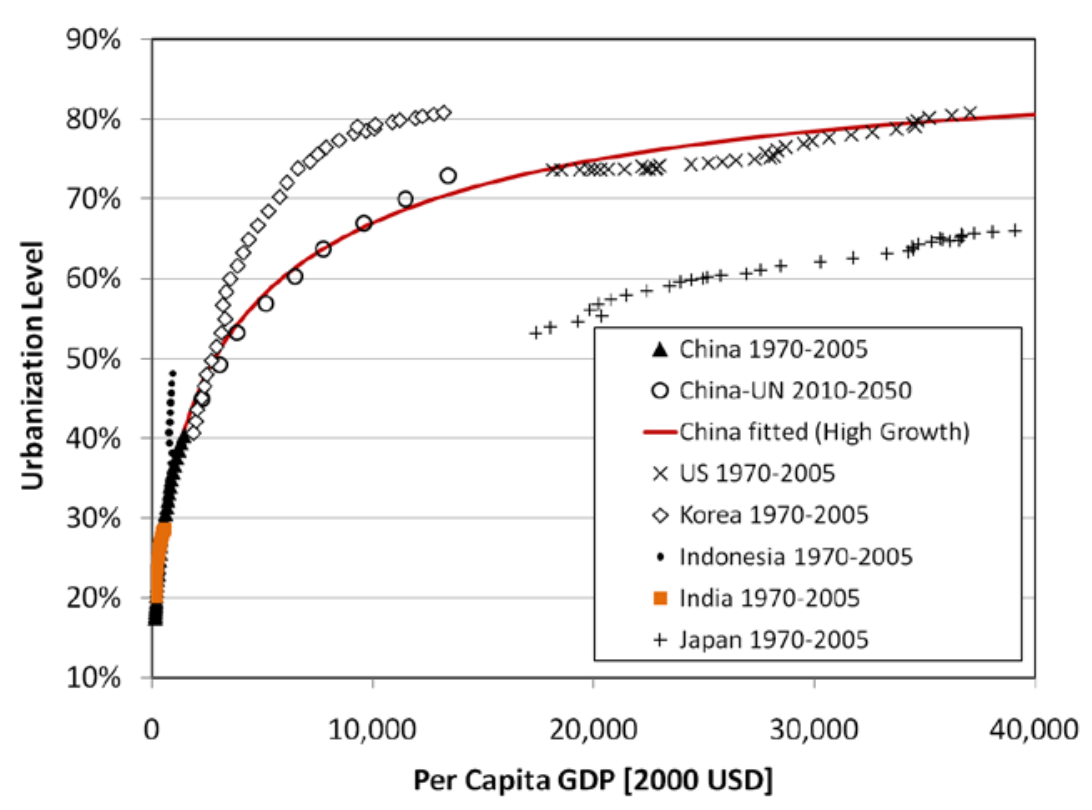

Figure 4: Selected countries' historical urbanization, UN's prospect of China's urbanization by 2050, and our projection of China's urbanization by 2100 (Source: WDI [37] and UNDP [38]) 
Nonetheless, there is strong empirical evidence that urbanization is correlated to GDP (Figure 4). At the same time, it is also clear that non-income effects have played an important role in determining historical urbanization rates, given the wide range of urbanization levels among countries for similar income levels (Figure 4). Hence, for the model presented here, we assume a non-structural relationship between urbanization and total per-capita income. As per capita income rises, the urbanization level increases and converges to a certain preset level with parameters fitted to historical urbanization trend as well as UN's urbanization prospect through 2050 [38]. The relationship used in the model is as follows:

$$
\text { Ulevel }_{t}=\text { Ulevel }_{\text {MAX }}\left\{1-\exp \left(-\alpha \cdot \text { Income }_{t}{ }^{\beta}\right)\right\} \quad \text { Eqn. } 1
$$

where Ulevel $_{t}$ and Income $_{t}$ are urbanization level and per capita GDP at time $\mathrm{t} ; \alpha$ and $\beta$ are parameters to fit; and Ulevel $_{\text {MAX }}$ is the asymptote of China's urbanization.

For this study, the urbanization asymptote has been set at $86 \%$. This number is drawn from UN's 2050 urbanization prospect for so-called 'more developed regions.' As a comparison, the UN's 2010 estimates of urbanization level are $89 \%$ for Australia, $83 \%$ for South Korea, $82 \%$ for the U.S., $80 \%$ for UK, 74\% for Germany, and 73\% for Russia. All countries combined, UN's 2010 estimates of urbanization level are 75\% for 'more developed regions' and 45\% for 'less developed regions' [38].

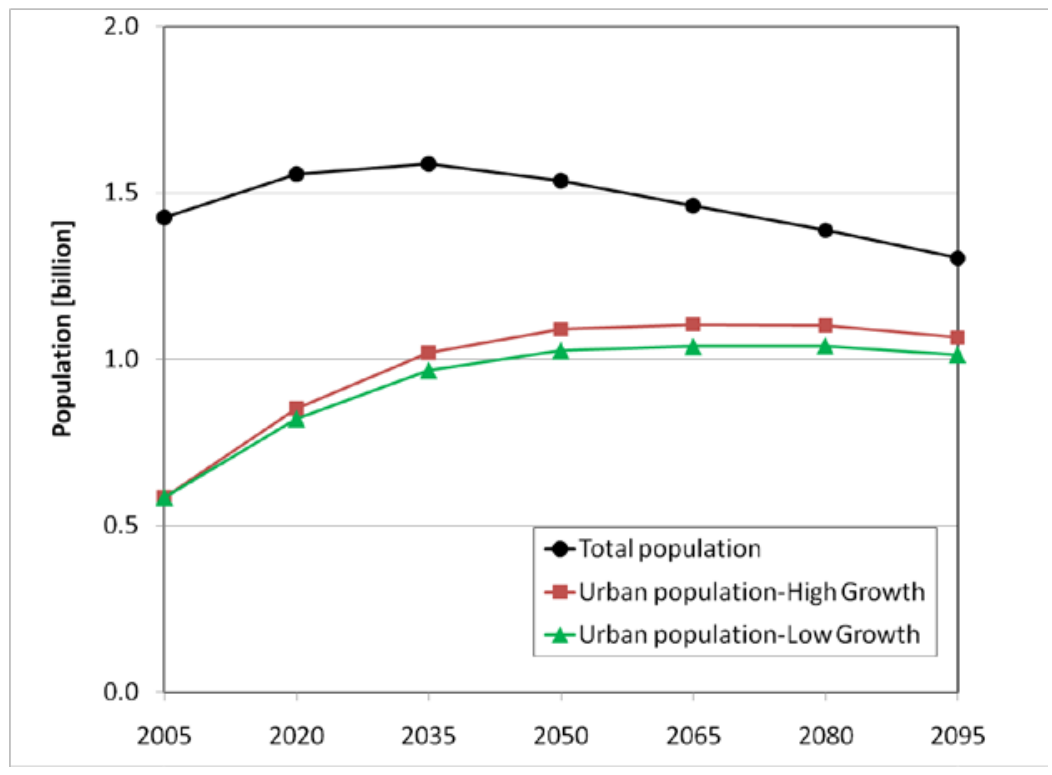

Figure 5: Urban and rural populations for different GDP scenarios

The result of this formulation and associated assumptions is that China undergoes fast urbanization in the first half of the century, ultimately taking the path of the U.S. (Figure 4 and Figure 5). By 2050 , urbanization exceeds $71 \%$ in the high growth case and $66 \%$ in the low growth case in 2050 , 
reaching $81 \%$ and $77 \%$, respectively, by the end of the century. For comparison, the UN projects that the urbanization rate will rise from $40 \%$ in 2005 to $73 \%$ in 2050 [38].

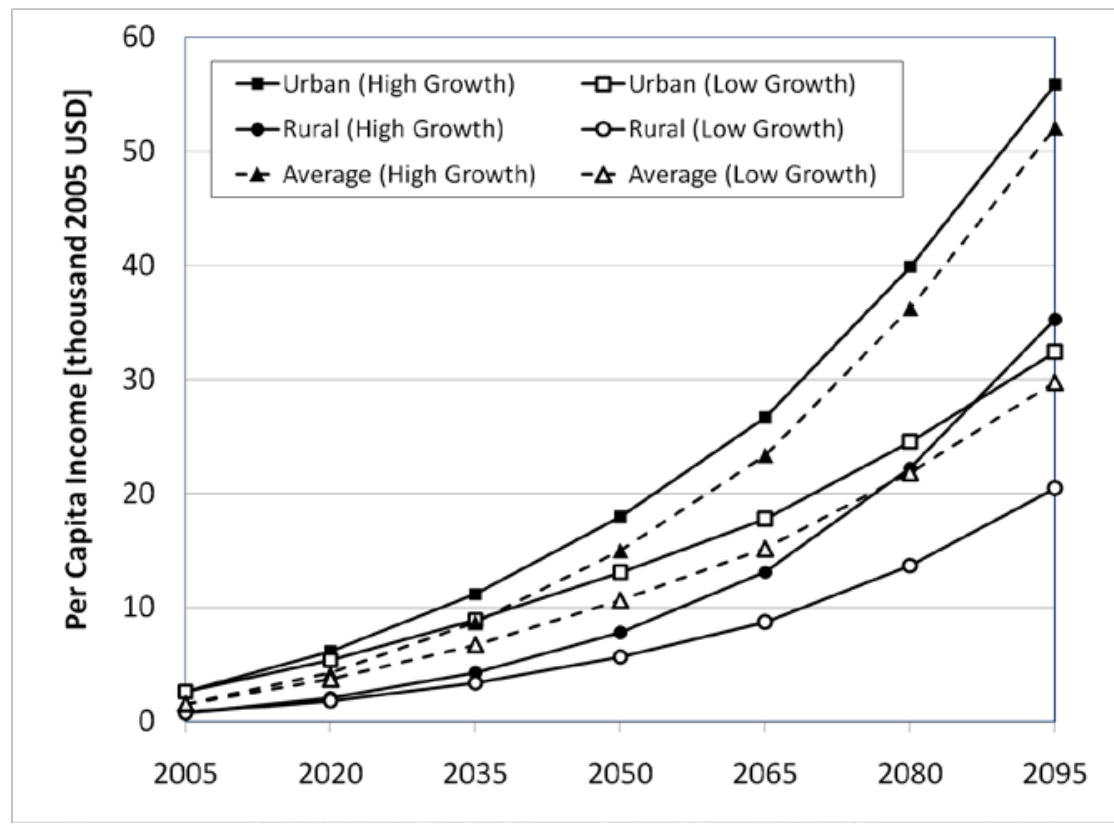

Figure 6: Urban and rural per capita incomes and national average incomes for different GDP scenarios

Representing the change in urban and rural populations is not sufficient to determine other building energy demand determinants such as floorspace and service demands. It is also necessary to represent the change in urban and rural incomes and to do so in a way that is consistent with the urbanization scenarios. As China's current pace of urbanization slows down, the country's urban-to-rural per capita income ratio, which had steadily increased from 2.4 of 1997 to 3.4 of 2005 [2], should also start to decline. Unfortunately, there is little empirical literature to base an evolution of this ratio over time. We therefore again employ a non-tructural model, assuming that the urban-to-rural per capita income ratio declines geometrically and reaches unity by $2150 .{ }^{10}$ This approach leads to income ratios of 2.3 in 2050 and eventually of 1.6 in 2095. It is important to note that this assumption is invariant to the urbanization rate. The resulting per-capita results are shown in Figure 6.

\footnotetext{
${ }^{10}$ See Grubler, et al. [39] or Vuuren, et al. [40] for similar assumptions made to project how subnational or subregional per capita income disparity would evolve over time.
} 


\subsection{Building Floorspace}

Working from left to right in Figure 3, the second key issue is the representation of the expansion of floorspace for each of the three building types used in the model. Several factors were considered in this calculus. First, floorspace growth is strongly linked to income growth (Figure 7 and Figure 8 below). Second, floorspace is a function not just of demand, but also of supply. Geographical and institutional constraints may make building floorspace increasingly scarce (and thus more expensive) particularly in urban areas. Hence, the model needs some representation of floorspace supply. Finally, income is not the only factor that influences the demand for floorspace. Demand for floorspace may also change with market prices of purchasing or renting a building, prices of other ancillary services such as utilities, insurance, maintenance, and, most important for this study, energy services. The fact that energy service prices are incorporated into the floorspace calculation is important because energy costs to operate given building floorspace may rise rapidly, particularly in a price on carbon policy regime, making the expansion of building floorspace less affordable. Nonetheless, despite the inclusion of this effect, energy price changes do not substantially alter the demand for floorspace because other building costs are far larger.

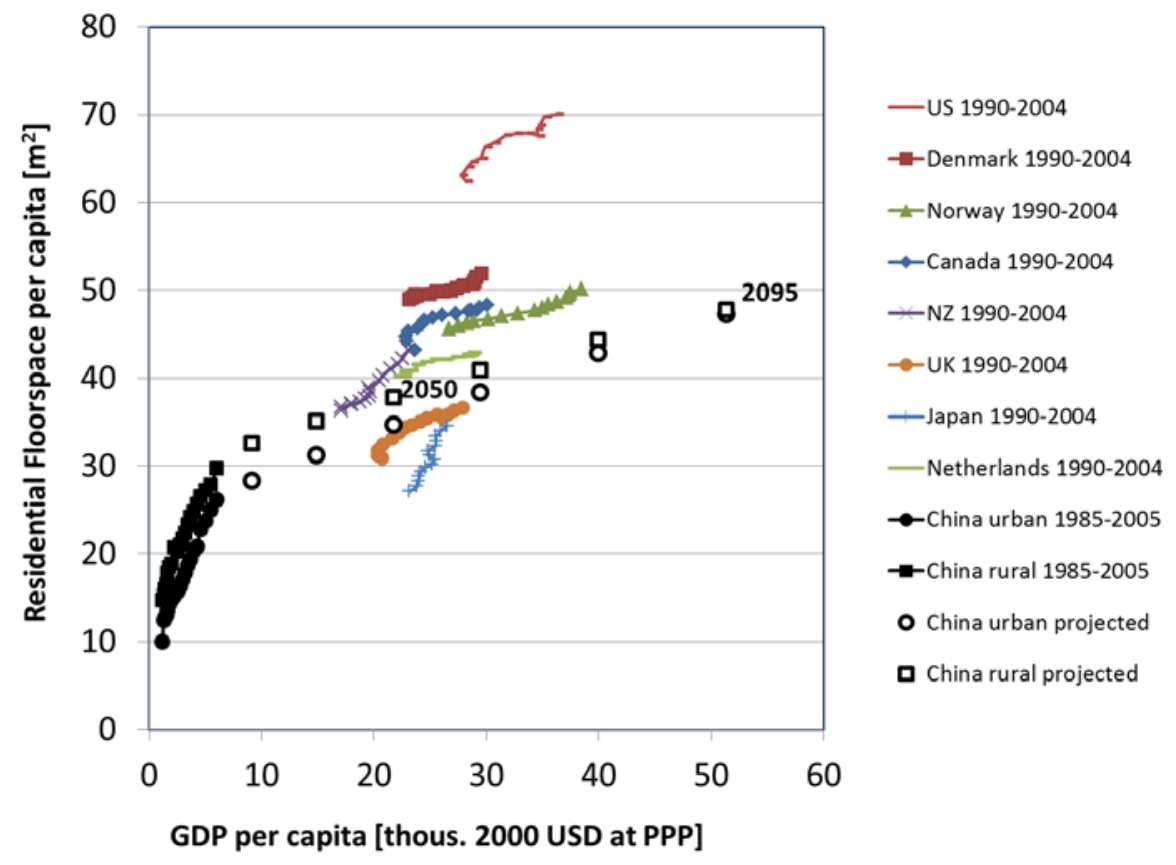

Figure 7: Development of residential floorspace per capita: international comparison (Source: Odyssee [15], USBED [16], OECD [42], and our model results for the high-growth no-policy case) 


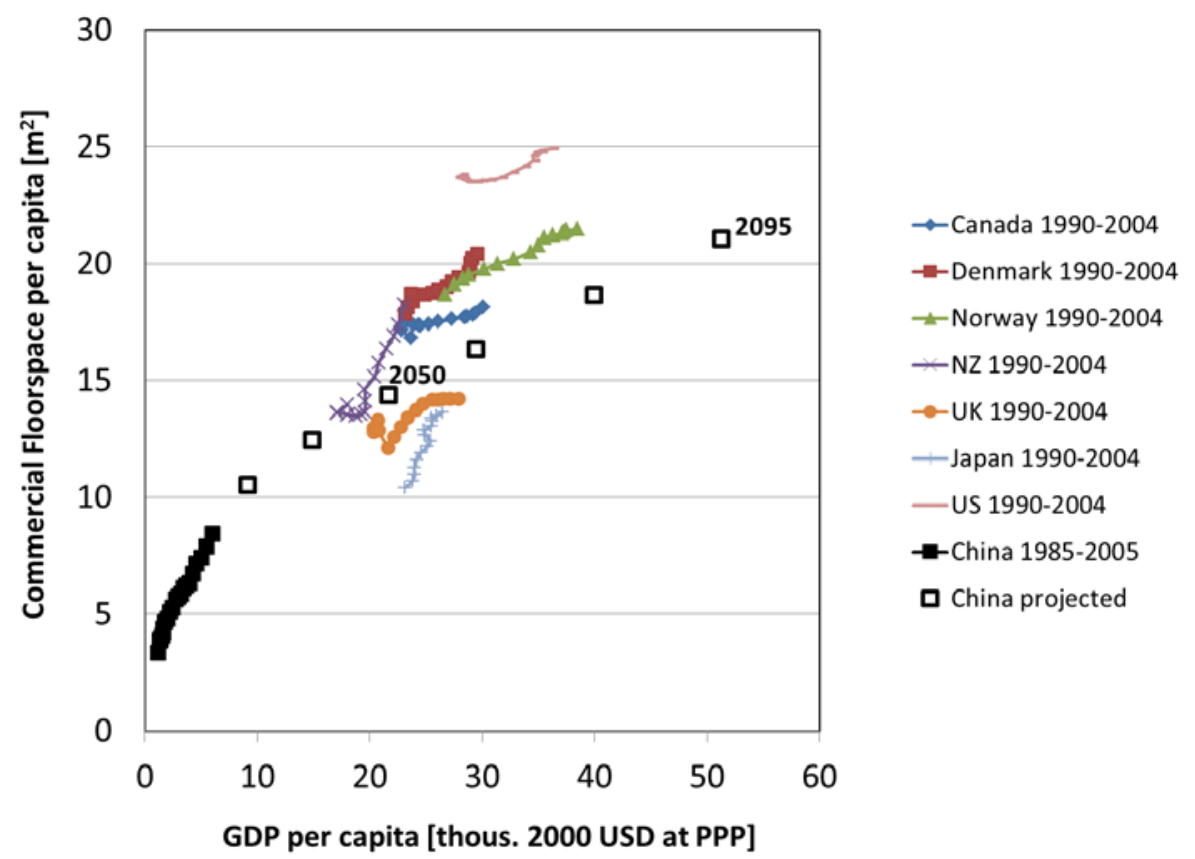

Figure 8: Development of commercial floorspace per capita: international comparison (Source: Odyssee [15], USBED [16], OECD [42], and our model results for the high-growth no-policy case)

To capture these various factors, per capita demand for a building [ $\mathrm{m}^{2} / \mathrm{capita}$ ] in time period $t$ is given by

$$
q_{B, t}=k_{D} \cdot P_{B, t}^{\alpha} \cdot i_{t}^{\beta}
$$

where $P_{B, t}$ and $i_{t}$ are building price per unit of floorspace and per capita income in period $t$, and $\alpha$ and $\beta$ are the price and income elasticities of the demand for building. Unobserved effects are captured in the calibration parameter $k_{D}$. Here, building price $P_{B, t}$ faced by a potential resident is the sum of the price of purchasing (or renting) a unit of floorspace and the price of having various energy services delivered to the floorspace. The resulting specification of building price is given by

$$
P_{B, t}=P_{F, t}+\sum_{j} P_{j, t} \cdot d_{j, t}
$$

where $P_{F, t}$ indicates the price of purchasing a unit of floorspace (in $\left.\left[\$ / \mathrm{m}^{2}\right]\right), P_{j, t}$ is the price of providing a unit of energy service $j$ (in [ $\$ / G J$-output]), and $d_{j, t}$ is the density of building energy service $j$ delivered to the floorspace in time period $t$ (in [GJ-output $\left./ \mathrm{m}^{2}\right]$ ), which will be discussed in detail in the next section. 
In this way, the demand for a building is allowed to respond not only to floorspace price itself but also to the aggregate price of delivering energy services required to the floorspace.

The market clearing size and price of building floorspace is obtained by equating the total demand for building floorspace with the supply of building floorspace $\left[\mathrm{m}^{2}\right]$, which is given by

$$
Q_{t}=k_{S} \cdot P_{F, t}^{\gamma} \quad \text { Eqn. } 4
$$

where $\gamma$ is the price elasticity of the supply of a building and $k_{S}$ is a calibration parameter capturing unobserved effects on the supply. The greater the elasticity, the lower the marginal cost of expanding building floorspace for given period of time.

This system of equations (Eqn. 3 and Eqn. 4) necessarily makes a number of simplifying assumptions. First, it assumes that there is no noticeable lag in market adjustment to income shifts. In reality, however, supply may be fixed in the short run and prices will adjust to equate demand with the fixed supply. This might make projections based on the assumption of instantaneous market equilibrium somewhat optimistic. Second, the potential decline in household size and changes in household age structures are not taken into account in the demand-side representation. For example, as the size of households shrinks, per capita residential floorspace might expand even without income growth, and thus per capita energy consumption might increase. Third, potential changes in building supply and demand technologies are not considered. For example, modular building construction practices may lead to a more elastic supply of building floorspace, and more efficient utilization of building space enabled by integrated building design and compact building technologies may decrease the demand for building floorspace in the future.

Setting the appropriate elasticities for this system of equations is a matter of some art. The challenge is particularly difficult for China, given the absence of complete time-series or detailed crosssectional data for building market transactions, particularly for those years after the privatization of real estate in China. Acknowledging the difficulty, we chose a set of elasticity numbers that allow for a longterm projection of per capita building floorspace reasonably consistent with other developed countries experiences. We assumed that the price and income elasticities of the demand for a building are -0.4 and 0.4 for both urban residential and commercial building consumers and -0.15 and 0.15 for rural residential building occupants; and the price elasticities of the supply of building floorspace are set to 0.75 for both urban residential and commercial buildings and 1.0 for rural residential buildings. ${ }^{11}$

\footnotetext{
${ }^{11}$ In a similar simultaneous equation framework based on aggregated annual data from 1987 to 2007 , Chow and Niu [41] provide estimates of income and price elasticities of demand and price elasticity of supply in the Chinese urban residential sector. Various model specifications suggest that the long-run income elasticity of demand for urban
} 
These numbers are based on the general assumption that demands for urban residential and commercial buildings are more price- and income-responsive than that of rural residential buildings, whereas the supply of rural residential buildings is more price-responsive than the supplies of urban residential and commercial buildings. The conjecture is that a greater number of building purchase alternatives and energy technology options are available in urban or commercial applications, owing to broader access to information and improved transport and energy infrastructures. This leads to greater price and income responsiveness in urban and commercial applications than in rural areas. By contrast, expanding the supply of building floorspace is much easier in rural areas than it is in urban or commercial areas due to rapid urbanization mainly driven by rural-to-urban migration. This results in greater price responsiveness in the supply of rural building floorspace. Note that, in the model, urban and rural residential building demands shift with urban and rural income, respectively, whereas commercial building demand shifts with total income because it can be thought of as an essential input for the economy.

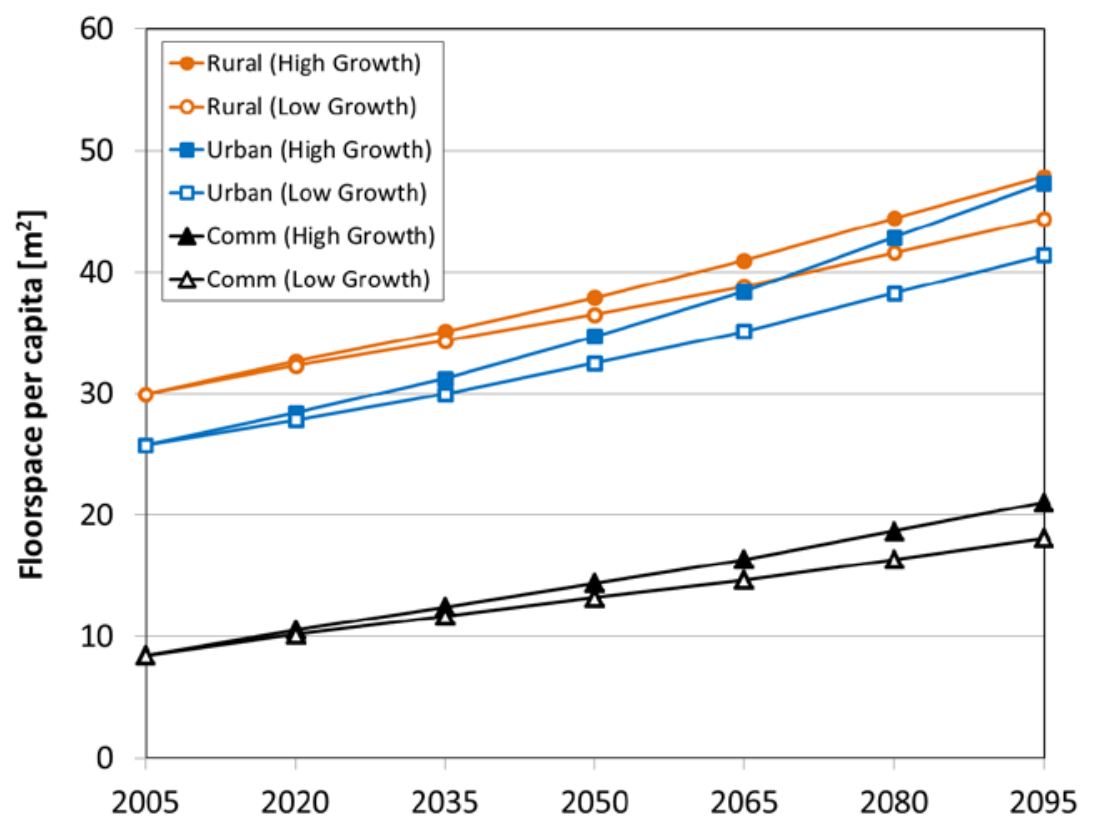

Figure 9: Development of per capita floorspace for China buildings in the no-policy scenarios

housing is between 0.7 and 1.1, the price elasticity of demand between -0.3 and -0.7 , and the price elasticity of supply around 0.8 . These estimates roughly match with our parametric assumptions except for the income elasticity of demand. We conjecture that our moderate income elasticity assumption (0.4) may better predict the century-long evolution of the urban housing market in rapidly growing China; and this moderate income effect makes China's floorspace expansion more consistent with other countries' experience with income growth. 
Based on these assumptions, and applying the two different economic growth trajectories discussed in Section 2.4, per capita floorspace increases by $120-150 \%$ by the end of the century for commercial buildings, $60-85 \%$ for urban residential buildings, and 50-60\% for rural residential buildings all in the nopolicy scenarios (Figure 9). The urban-to-rural gap in per-capita floorspace narrows down over time in all cases. This is mainly because the assumed urban-to-rural difference in income elasticities, which leads to faster expansion of urban floorspace than rural floorspace over the century-this effect indeed more than offsets the price-induced effect that limits the expansion of urban floorspace more than that of rural floorpace. Under the assumptions in this study, China's residential and commercial per capita floorspace by the end of the century would be close to the current levels of some European countries such as Norway and Denmark, but still far lower than those of the U.S., by the end of the century (Figure 7 and Figure 8).

\subsection{Representing Building Energy Service Demands}

Again, working from left to right in Figure 3, the third challenge is to determine the energy services (e.g., lighting, heating, cooling) that households will demand per unit of floorspace. Service demand should increase with income and decrease with service price. However, it is not reasonable to simply apply constant price and income elasticities in a long-term model with substantial income growth. As incomes grow, people do not somehow decide that a room temperature of $100^{\circ} \mathrm{F}$ during the winter is better than $72^{\circ} \mathrm{F}$, nor do they demand overly bright lighting for illumination. In economic terms, there is a satiation with energy service comfort (or, equivalently, a "bliss" point), below which the marginal utility of an energy service is positive and above which the marginal utility turns negative [43-44].

Consequently, the magnitude of the income and price effects is likely to fall as incomes increase.

Empirical research confirms that income and price elasticities of energy service demands decrease with increasing income [45]. ${ }^{12}$

To capture this satiation behavior, we take a two-step approach to the development of service demands. First we identify a satiated demand for services per unit of floorspace. This satiated demand represents the maximum that consumers might demand and is based strictly on technical parameters. The satiated demand is exogenously defined in the model.

We then calculate the actual demand as a function of the satiated demand, income, and service prices. In total, then, demand for any given service, $j$, per unit of floorspace is given by

\footnotetext{
${ }^{12}$ One interpretation of this decreasing price elasticity is that the share of total budget allocated to energy expense declines as income grows. The result is that the demand for energy services is less affected by a variation in energy prices. Also, the extent to which the demand can rise with income, either through owning an additional unit of enduse equipment or intensifying equipment uses, also decreases as income grows, which makes the demand less responsive to income changes.
} 


$$
d_{j}=k_{j} \cdot \bar{q}_{j} \cdot \phi_{j}\left(P_{j}, i\right)
$$

where $k_{j}$ is a calibration parameter, $\bar{q}_{j}$ is the satiated demand for the service, and $\phi_{j}\left(P_{i}, i\right)$ gives the effect of economic decision making representing the fraction of the satiated demand that is actually demanded, based on the price of the service, $P_{j}$, and per-capita income, $i$. For heating and cooling, the satiated demand must take into account both climate conditions and physical building characteristics. Satiated demand for heating and cooling is specified is given by:

$$
\begin{array}{lr}
\bar{q}_{H}=H D D \cdot \eta \cdot r-\lambda_{H} \cdot I G & \text { Eqn. } 6 \\
\bar{q}_{C}=C D D \cdot \eta \cdot r+\lambda_{C} \cdot I G & \text { Eqn. } 7
\end{array}
$$

where $H D D$ and $C D D$ are heating and cooling degree days $\left[\right.$ day $\left.{ }^{\circ} \mathrm{C}\right]$ representing the annual requirement of space heating and cooling to achieve the specific, comfort-driven indoor temperature point $\left(18^{\circ} \mathrm{C}\right) ; \eta$ is thermal conductance (or U-value) $\left[\mathrm{GJ} / \mathrm{m}^{2}\right.$ day $\left.{ }^{\circ} \mathrm{C}\right]$ indicating the extent to which indoor temperature is susceptible to outdoor weather; and $r$ is building floor-to-surface area ratio representing the size of building shell exposed to outdoor temperature. $I G$ is the amount of building internal gains $\left[\mathrm{GJ} / \mathrm{m}^{2}\right]$, calculated endogenously in the model based on the demand for other building services such as lighting, and $\lambda_{H}$ and $\lambda_{C}$ are internal-gain scalars accounting for the potential mismatch of the time when space conditioning is required and the time when the internal gains are produced.

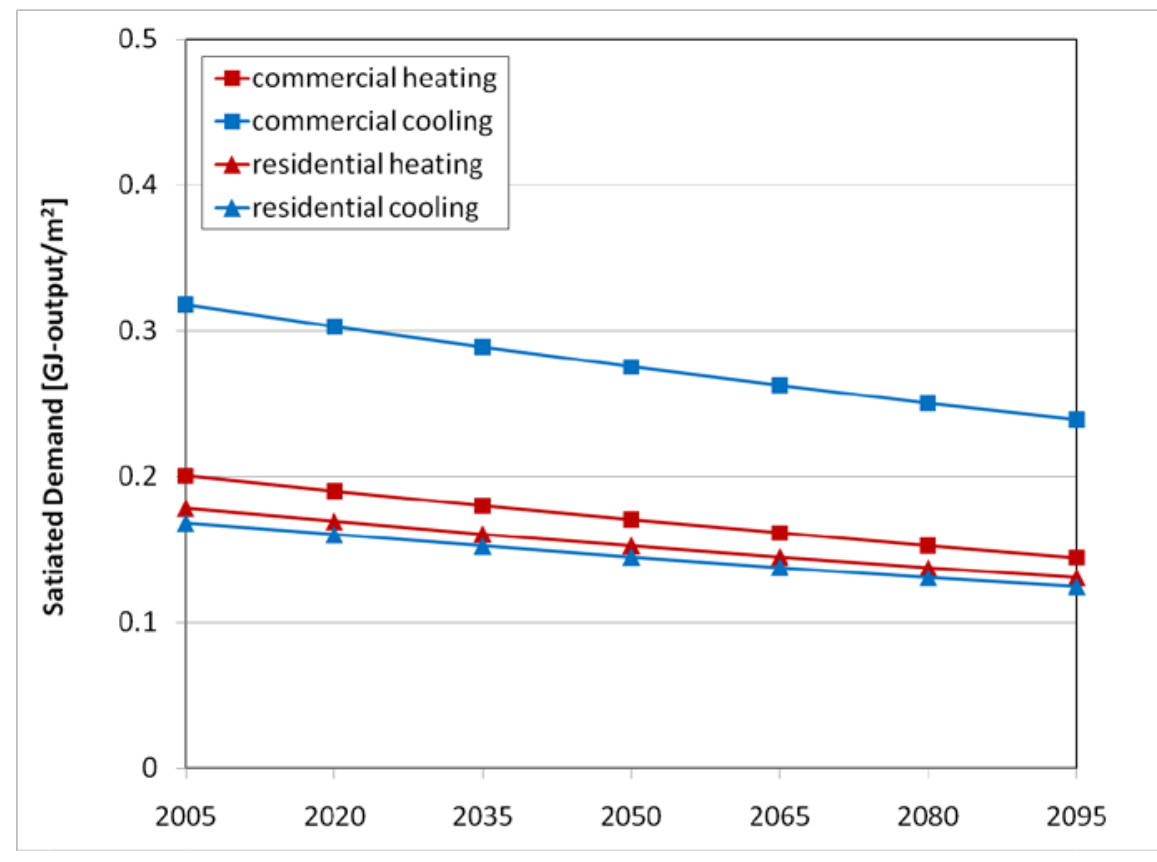

Figure 10: Satiated demands for heating and cooling services in commercial and residential buildings under the high-growth no-policy scenario 
It is important to note that satiated demands for heating and cooling change over time largely as a function of building shell characteristics but also in response to changes in internal gains (Figure 10). In future research, they could also be made to change in response to a changing climate, but this capability is not exercised in this study. Shell improvement leads to decreases in satiated demands for both heating and cooling services, dominating the countervailing effect of building internal gains.

In contrast to the structural model used to develop satiated demands for heating and cooling, those for cooking, lighting, appliances, and equipment services are simply applied exogenously. All other satiated demands are assumed to be constant over time

Satiated demands were benchmarked against the current energy services delivered to the U.S. buildings, assuming that U.S. service levels have roughly reached the points of satiation. U.S. building energy services per unit of floorspace in 2005, taken from Kyle et al. [4], were used for this study. The satiation demands for heating and cooling services in Chinese buildings were calculated by adjusting the U.S. numbers with the ratios of heating and cooling degree days between the two countries to account for their differences in climate conditions. ${ }^{13}$ For the satiation demands for the other services, a fixed multiplier of 1.3 was applied to the U.S. values to approximate the difference in the occupancy rates between the China and the U.S. Note that many of these demands are more associated with occupancy than with floorspace in total.

We now turn to the behavioral component of choice, $\phi_{j}$. The price and income effects are represented as follows:

$$
\phi_{P, j}=1-\exp \left(-\frac{\ln 2}{\mu_{j}} \frac{i}{P_{j}}\right)
$$

where $P_{j}$ is the price of energy service $j$ and $i$ is per capita income. $\mu_{j}$ is refered to as the saturation impedance. It helps to define the degree of saturation given a particular affordability of the service, or $i /$ $P_{j}$. In words, $\mu_{j}$ is the level of affordability required to achieve half of its satiation level, or $\bar{q}_{j} / 2$. Given the same affordability, the higher the level of saturation impedance for an energy service, the lower the level of delivered service. This satiated demand model gives not only the behavior of demand satiation, it also has a great advantage over a constant elasticity formulation in that it has built-in attenuation of income and price elasticities with the level of income (Figure 11).

\footnotetext{
${ }^{13}$ We used the population-weighted national heating and cooling degree days in China and the U.S., estimated by the World Resource Institute (http://cait.wri.org/downloads/DN-HCDD.pdf)
} 


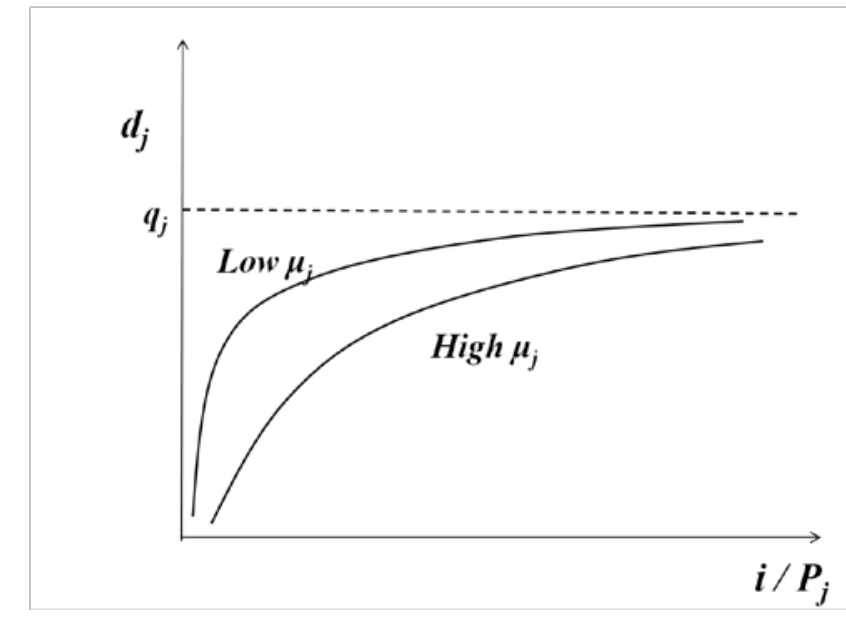

Figure 11: A schematic illustration of the saturation of a building service demand
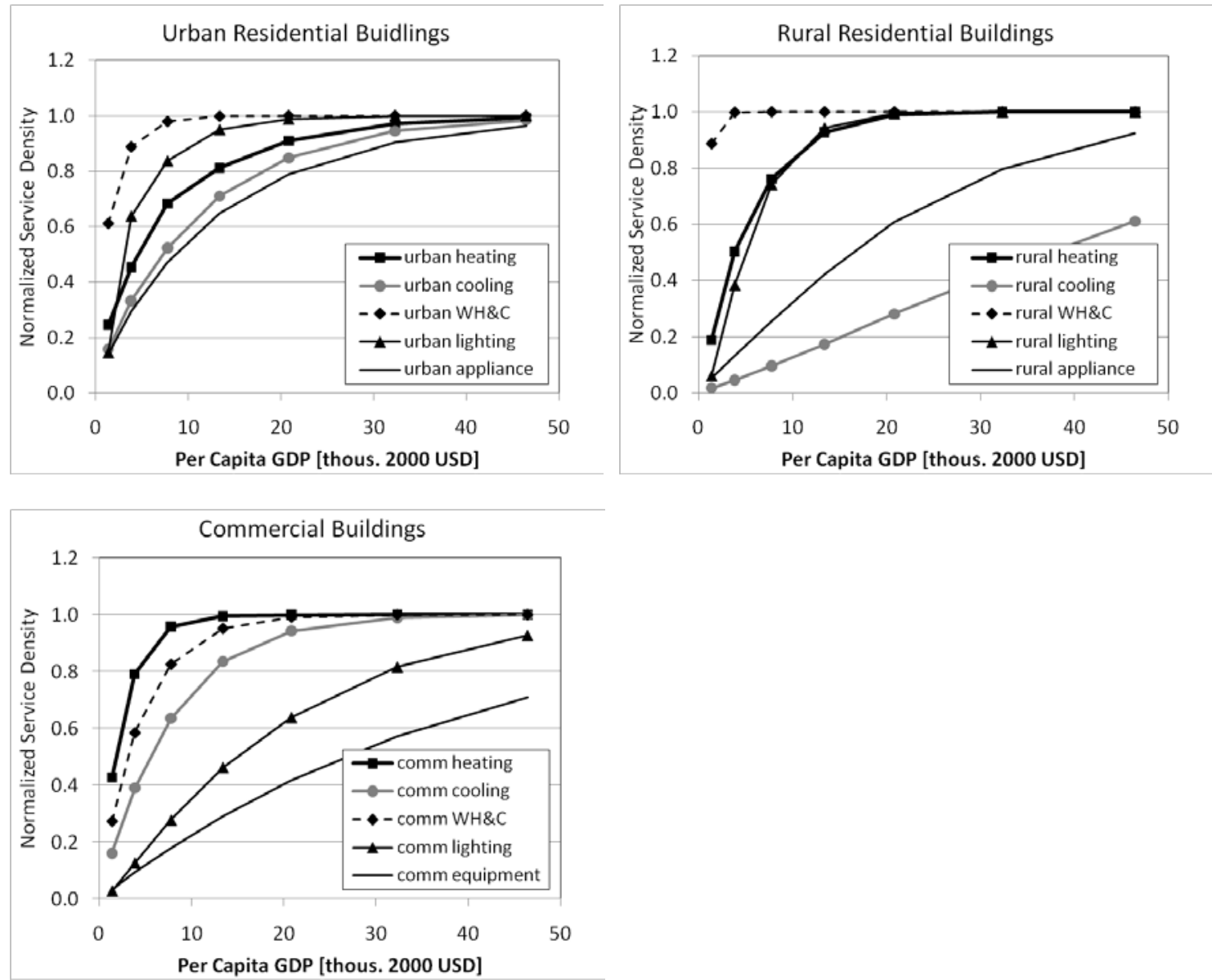

Figure 12: Energy service per unit of floorspace in urban residential, rural residential, and commercial buildings with respect to China's per capita GDP during the century in the high-growth no-policy case. 
For this study, the saturation impedance for each service was calculated from the ratio of its baseyear service demand to the assumed satiated demand. This parameterization along with the changes in the model over time gives a time pathway of saturation for each service and each building sector (Figure 12). Note that each service is associated with a different saturation impedance and therefore has a different relationship between service affordability and saturation. Heating and cooling penetrate most quickly in commercial buildings, water heating and cooking in rural buildings, and lighting and appliances in urban buildings. For residential buildings-particularly in rural areas-water heating and cooking demand has almost reached satiation today. By the end of the century, most of the energy services are saturated or nearly saturated in all of the three building sectors, with the exception of cooling in rural buildings and equipment in commercial buildings. These two services are demanded least among the service types in 2005 , less than what their service affordability may indicate, suggesting a high level of saturation impedance. Note also that that these projections are indexed to their points of satiation, so that the actual satiated demands can change over time (Figure 10).

\subsection{Technology Assumptions}

The next modeling issue as we work from left to right in Figure 3 is the specification of technologies for converting fuels into useful building services (e.g., air conditioners, lights, heaters). Two building technology scenarios were established for this study, one representing business-as-usual, or evolutionary technology development and deployment (Reference Technology) and one representing accelerated technology improvement case, enabled by stricter building codes/standards or large-scale building energy efficiency programs promoting overall efficiency of building energy technologies (Advanced Technology). Base-year technology efficiencies, to which base-year service demands were calibrated, were chosen from several studies on China buildings, including Larson et al. [46], Zhou \& Lin [11], Zhou et al. [10], and Evans et al. [47]. Tables A1 and A2 (in Appendix) list representative building shell and end-use technologies delivering energy services to residential and commercial buildings, as well as their technology advancement assumptions.

There are two important caveats regarding the treatment of building end-use technologies in this model. First, the model represents the average efficiencies of technology stock in place. The model does not represent the turn-over dynamics of technology stock. The smooth efficiency trajectories specified above presume gradual replacement of existing lower-efficiency technologies or practices with new higher-efficiency ones. The second related issue is that because the model is based on discrete technology options, the available technology options in any given time period are limited to those that have been put into the model. In this study, only a limited set of technologies was used to create the scenarios. For 
example, the model used in this study assumes that only a single electric air conditioner with a fixed efficiency at any point in time. This limits the technological response to changing prices within this technology class. At the same time, there are many options for technological responses across technologies or fuels. For example, heating can be supplied by gas furnaces, electric resistance heaters, electric heat pumps, coal furnaces, biomass furnaces, and oil furnaces.

\subsection{Other Design Issues}

\subsubsection{Varying Service and Fuel Preferences}

The dichotomy of urban and rural in our model allows for changes in urban and rural preferences for individual energy service demands and fuels. The urban-to-rural income gap does not fully represent the differences in energy consumption behavior between urban and rural consumers. All else equal, for instance, detached single-family houses dominant in rural areas would require more heating and lighting services per unit of floorspace than multi-unit and high-rise apartment houses pervasive in urban areas, and commercial buildings would demand more cooling service per unit of floorspace than residential buildings. Our service demand model attempts to capture such differences by implementing different levels of saturation impedance — calibrated to base-year energy use profiles—across the buildings sectors. For instance, saturation impedance for heating is the lowest in rural residential buildings, followed by commercial and urban residential buildings; and saturation impedance for cooling is the lowest in commercial buildings, followed by urban and rural residential buildings.

Beyond socio-cultural differences in service preferences, people in different buildings sectors may have different fuel preferences inherently because they have different fuel options available. For example, rural consumers have limited access to district heat and gas and limited access to electric power. They have less restricted access to traditional biomass. In the model, this regional difference in fuel options continues to remain largely the same, except for the limited introduction of gas in rural areas starting in 2020. Varying fuel options such as these and associated fuel choice preferences will lead to different energy service costs and different service expansion behavior across the three buildings sectors that may not fully explained simply by differences in income and service preferences. The next two subsections discuss about the two major sources of urban-to-rural differences in fuel choice-traditional biomass and district heating.

\subsubsection{Traditional Biomass}

The residential use of traditional biomass requires particular attention in creating a model of China's building sector. While most fuels delivered to China buildings are priced in the market, 
traditional biomass, which currently accounts for more than $80 \%$ of rural energy use, is not. This raises the question of whether rural residents might keep using traditional biomass simply because it is free. The modeling consequence of this assumption is that rural households will use increasing amounts of traditional biomass throughout the century.

To capture the decreasing preference for traditional biomass as incomes increase, the model incorporates the opportunity cost of time into the cost of traditional biomass. This approach is based on the notion that collecting traditional biomass requires a non-trivial quantity of labor. This labor will become increasingly costly as rural income grows. The model therefore assumes that the time-cost increases proportionately with per capita rural income; and the longer it takes to collect a unit amount of traditional biomass, the higher the time-cost will be. This results in an increasing trajectory for traditional biomass costs (Figure 13). In this study, the cost trajectory with the procurement time of 9 hours/GJoutput—about 2 hours of labor per person per week based on 2005 rural traditional biomass consumption-was chosen and allowed to compete with the costs of services delivered by other commercial fuels.

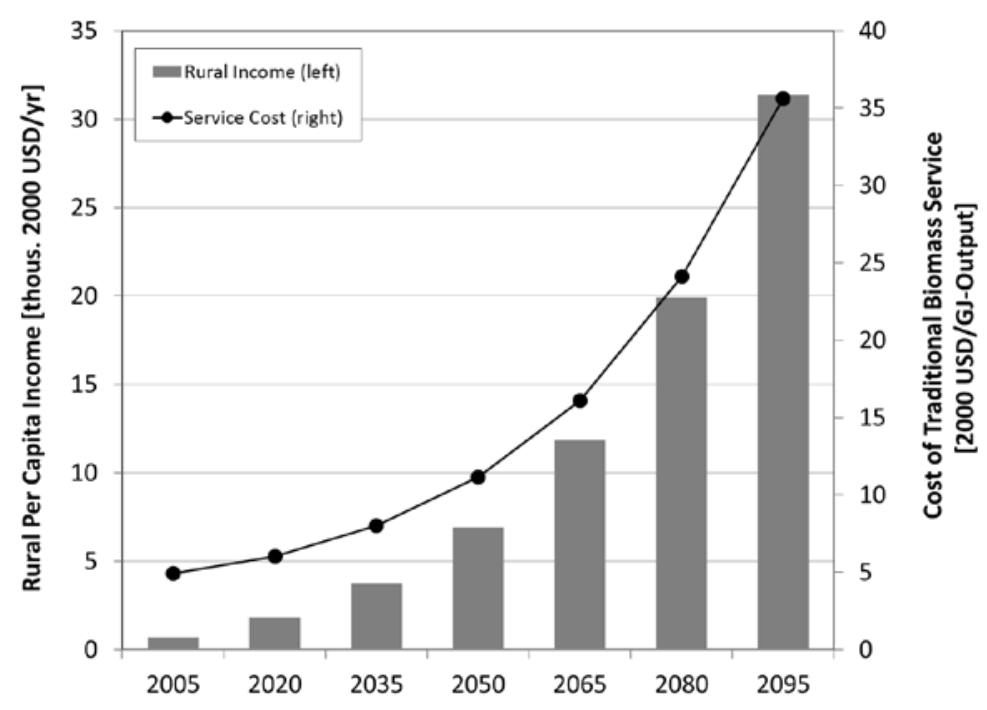

Figure 13: Development of the unit cost of space heating service delivered by traditional biomass with respect to its collecting time in the high-growth case.

\subsubsection{District Heating}

Another important aspect of the Chinese building sector is the prevalence of district heating in urban settings. Any model of the Chinese buildings sector must account for district heating. In the model 
presented here, district heat competes with other fuels to serve heating demand in urban residential and commercial buildings. District heat is produced from either conventional boilers or combined heat and power (CHP) generators, both types of which can be fired by coal, gas, oil, and biomass. In 2005, coal accounted for $92 \%$ of total fuel inputs to district heat, and gas and oil combined accounted for less than $8 \%$. Electricity co-generated by CHP systems, while negligible compared to the total amount of electricity produced by conventional power plants, is also counted in to serve the demand for electricity.

It is important to note that in this study, it is not possible to equip district heat systems with carbon capture and storage (CCS) technologies to cut their $\mathrm{CO}_{2}$ emissions. It is assumed that the size of district heating systems that are being installed in China's urban heating areas is not large enough to make the adoption of CCS systems economically attractive throughout the century, even under a $\mathrm{CO}_{2}$ policy. ${ }^{14}$ This has important implications for the role of district heating in climate policy scenarios, as will be discussed in the next section.

\footnotetext{
${ }^{14}$ To capture the economies of scale while minimizing heat loss, most cities currently have one or several larger district heating systems located within the city core, along with a number of smaller systems typically covering one or several buildings sited in suburban areas. Meyer \& Kalkum [14] reports that, in 1999, even larger CHP systems, which are usually located in high demand areas, had an average capacity of only about $20 \mathrm{MWe}$.
} 


\section{Results}

\subsection{Overview of Scenarios}

Eight scenarios are explored in this paper (Error! Reference source not found.) using the structure and parameters discussed in Section 3. The eight scenarios are constructed to explore the implications of variations along three dimensions: GDP growth, technological improvements, and the presence or absence of an idealized global carbon emissions control regime. All the other model assumptions, such as the socioeconomic drivers in other parts of the world and the characteristics of energy supply systems, are common across all scenarios. The GDP scenarios were described in Section 2.4. The technology assumptions were discussed in Section 3.5.

Table 2: Scenarios analyzed in the study

\begin{tabular}{l|l|l|l}
\hline Scenario Name & GDP Growth & Building Tech & Climate Policy \\
\hline $\begin{array}{l}\text { HighGrowth-RefTech } \\
\text { HighGrowth-AdvTech }\end{array}$ & High Growth & $\begin{array}{l}\text { Reference Tech } \\
\text { Advanced Tech }\end{array}$ & \multirow{2}{*}{ No climate policy } \\
\hline $\begin{array}{l}\text { LowGrowth-RefTech } \\
\text { LowGrowth-AdvTech }\end{array}$ & Low Growth & $\begin{array}{l}\text { Reference Tech } \\
\text { Advanced Tech }\end{array}$ & \\
\hline $\begin{array}{l}\text { HighGrowth-RefTech-Pol } \\
\text { HighGrowth-AdvTech-Pol }\end{array}$ & High Growth & $\begin{array}{l}\text { Reference Tech } \\
\text { Advanced Tech }\end{array}$ & $\begin{array}{l}\text { Global price on carbon } \\
\text { pathway achieving 550ppm } \\
\mathrm{CO}_{2} \text {-e }\left(3.7 \mathrm{~W} / \mathrm{m}^{2}\right)\end{array}$ \\
\hline $\begin{array}{l}\text { LowGrowth-RefTech-Pol } \\
\text { LowGrowth-AdvTech-Pol }\end{array}$ & Low Growth & $\begin{array}{l}\text { Reference Tech } \\
\text { Advanced Tech }\end{array}$ & \\
\hline
\end{tabular}

The emissions control policy is constructed to be consistent with stabilization of atmospheric $\mathrm{CO}_{2}$ concentrations at 550ppm. Mitigation is applied globally, because interactions between regions through trade and resource extraction are an important element of stabilization. To maintain consistency among scenarios, the emissions pathway for China is held constant across scenarios rather than letting emissions adjust across regions in response to other variations among scenarios. Although Chinese $\mathrm{CO}_{2}$ emissions remain constant across the scenarios, mitigation effort varies across the scenarios (Figure 14). The highgrowth scenarios require more mitigation effort than the low-growth scenarios; and the reference technology scenarios require slightly more mitigation effort than the advanced technology scenarios. The mitigation policy is implemented by applying a price to $\mathrm{CO}_{2}$ emissions everywhere in the Chinese and global economy. 


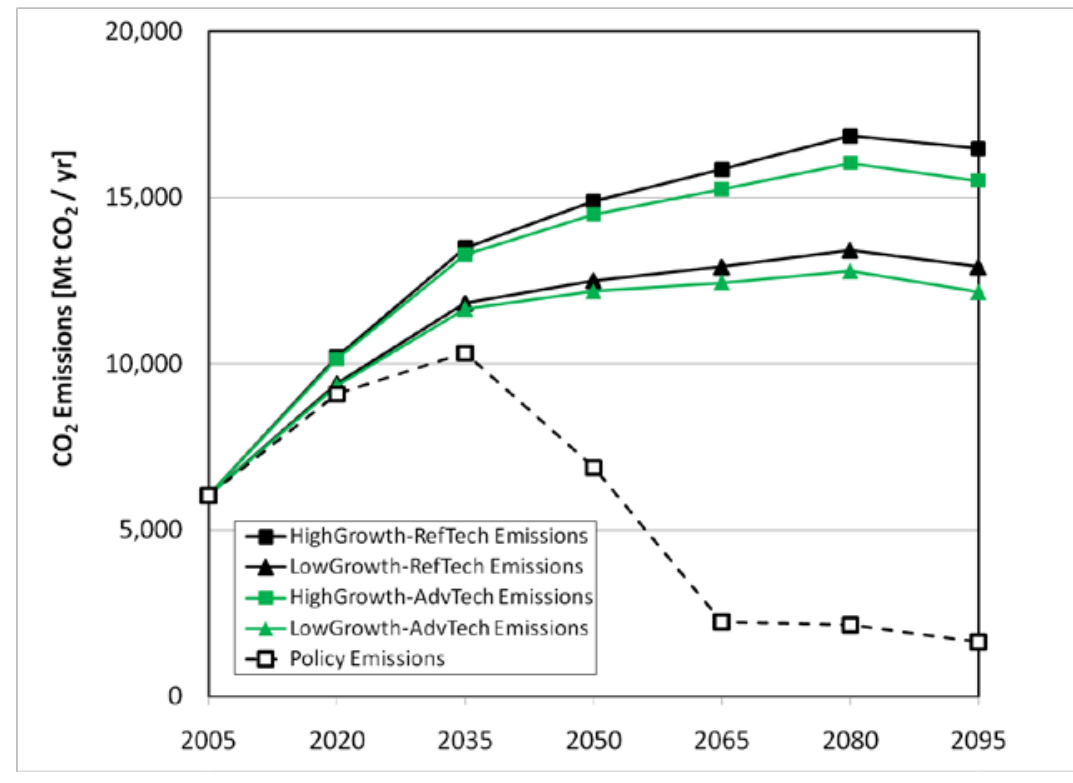

Figure 14: China's national $\mathrm{CO}_{2}$ emissions with and without its mitigation effort
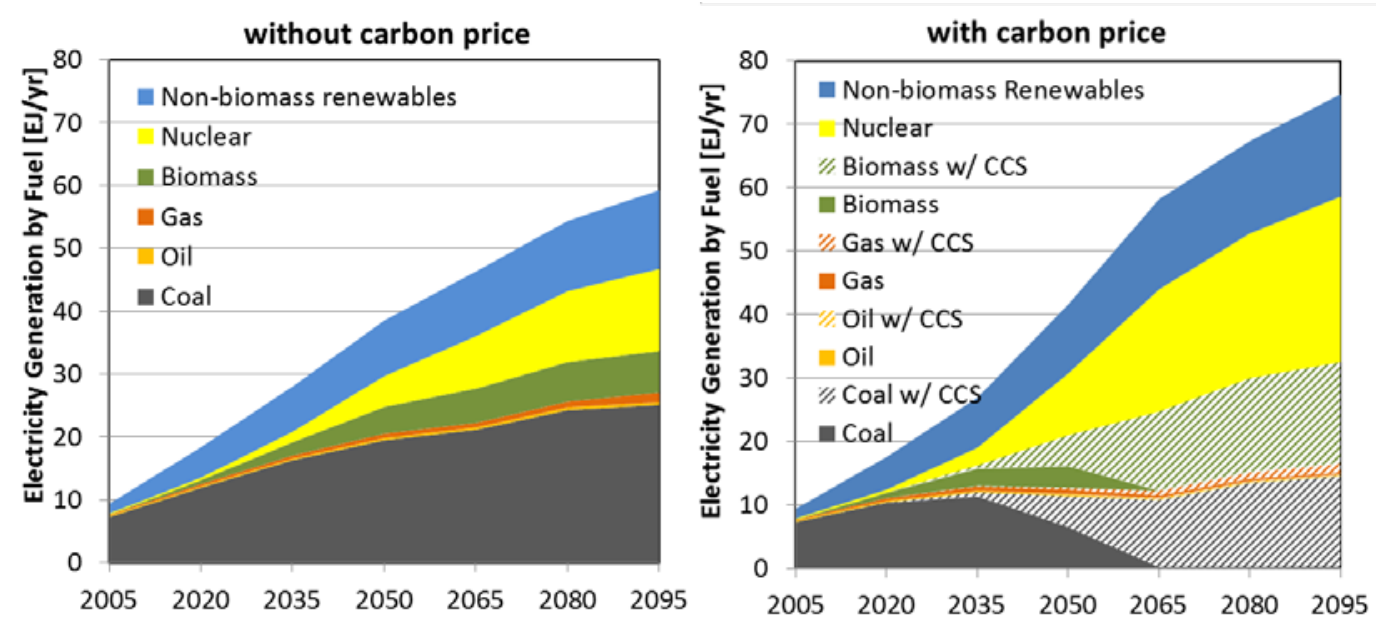

Figure 15: Electricity generation by fuel with and without the price on carbon in high-growth referencetechnology scenario

Because it will play into the nature of the building sector response to carbon policy, it is useful here to briefly discuss the influence of carbon policy on electricity generation. The implementation of the carbon policy dramatically shifts the electricity sector fuel mix and hence the associated emissions from electric power (Figure 15). Carbon policy spurs increased deployment of a suite of low-carbon technologies including nuclear power, fossil energy with CCS, bioenergy, and non-biomass renewable 
energy such as wind power and solar power. This rapid decarbonization of electricity is a well-established dynamic in previous mitigation studies (see, for example, Edmonds, et al. [48], Clarke et al. [5]).

It is also interesting to note that total electricity demand can increases in response to a carbon policy. This is also a common effect in mitigation studies. It can result in scenarios when the demand response in terms of lower energy demand is less powerful than that associated with fuel switching to electricity $[5,48]$.

\subsection{Building Energy Consumption in the Scenarios}

Not surprisingly, the no-mitigation-policy scenarios all exhibit a substantial increase in total building final energy consumption (

Figure 16). Under reference-technology assumptions, China's building energy consumption increases to 25-27 EJ by 2020 varying with the growth scenarios, which is slightly greater than IEA's projection of $24 \mathrm{EJ}$ [18]. In the long run, the sector's final energy consumption rises to 38-45EJ by 2050 and to 46-58EJ by 2095, surpassing China's total final energy consumption in 2005. With the mitigation policy, final energy consumption in buildings declines, but not dramatically. Relative to the no-policy scenarios, the building energy consumption decreases only by $1-3 \%$ by $2020,6-7 \%$ by 2050 , and $8-10 \%$ by 2095 , although the effect is substantial at the national level (Figure 14). Advanced technology reduces energy consumption in all scenarios, as expected.

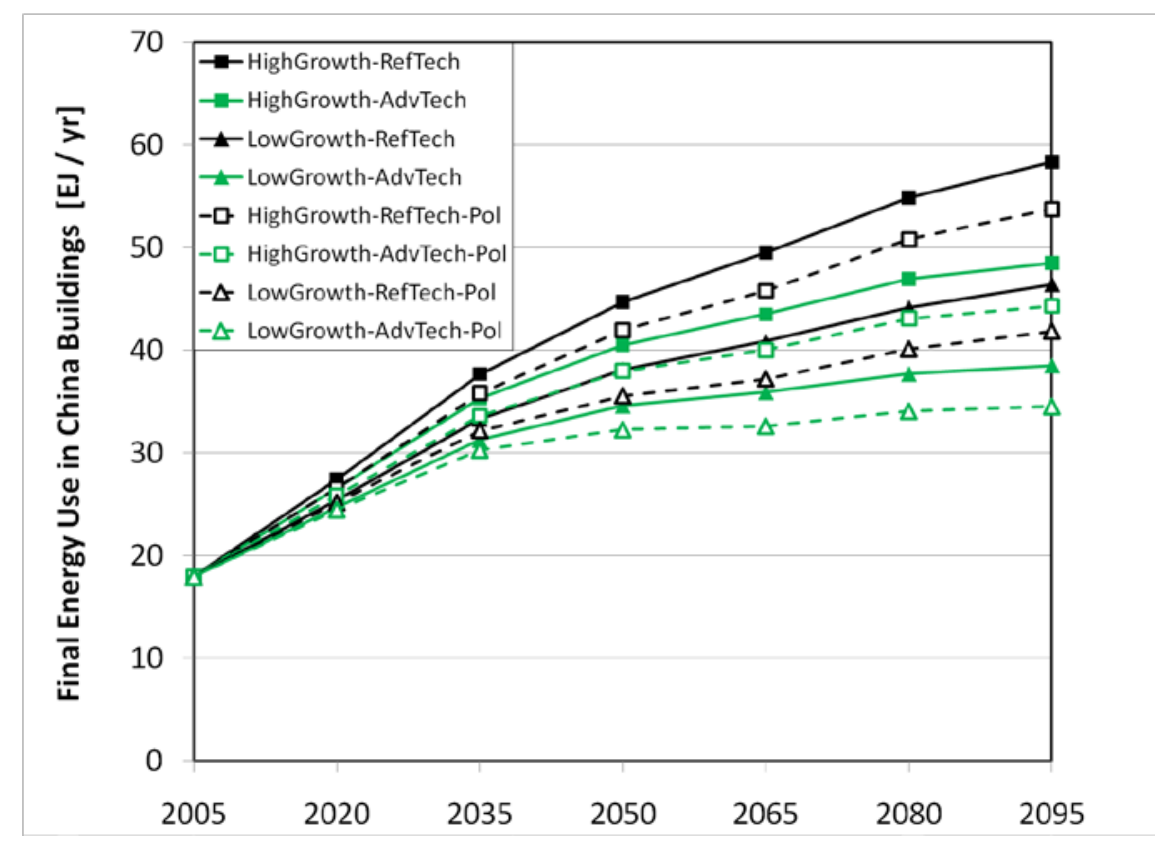

Figure 16: Final energy consumption by China buildings 
It is important to note that the technology assumptions have a larger effect on total final energy consumption than does the policy. To some degree this is simply a result of the technology assumptions that were chosen for the advanced technology case. However, it is also a reflection of the fact that building energy services are not highly responsive to changes in fuel prices, such as those that would result from a price on carbon. Indeed, this lack of responsiveness is one justification for the use of regulatory measures (e.g., building codes and standards). The effect of technology in these scenarios gives some sense of the potential benefits of these sorts of technology-focused policy measures.

\subsection{Fuel Mix in the Scenarios}

Variations along all three dimensions in the scenarios lead to differences in the fuel mix that is demanded by buildings. Several points are worth making regarding these results. First, there is a distinct difference in the effects of improved technology and the imposition of a price on carbon on the nature of fuel shares. Although improved technologies reduce final energy consumption as discussed above, they do not largely affect fuel shares (Figure 17). This is because the reduction comes from all fuel types in all services examined in this study. In contrast, carbon policy has a distinct electrification effect on building energy demands, while simultaneously lowering the shares of coal and district heat. This result emerges because the carbon policy affects the prices of fuels differentially, increasing those of fossil fuels such as coal and natural gas more than it does electricity. This is an important point. On the one hand, regulatory approaches may be more effective than carbon prices in reducing energy consumption in buildings in total, as discussed above. On the other hand, these policies operate independent of the fuels themselves; that is, they are agnostic about fuel choices. But fuel choice can be very important in a carbon constrained world, because decarbonization of electricity is among the most prominent effects of carbon policy and means for decarbonizing the energy system.

The fuel mix changes associated with a price on carbon can be illuminated by examining changes in the prices of fuels delivered to the buildings sector. Without the price on carbon, the prices of fuels remain relatively stable throughout the century (Figure 18). However, once the carbon price is imposed, the prices of more carbon-intensive fuels such as coal, oil, and biomass rise faster than the prices of less carbon-intensive fuels such as electricity (note that we assume the option to apply CCS in these scenarios). This means that fuel switching is more attractive under the policy case than the regulatory approach. 

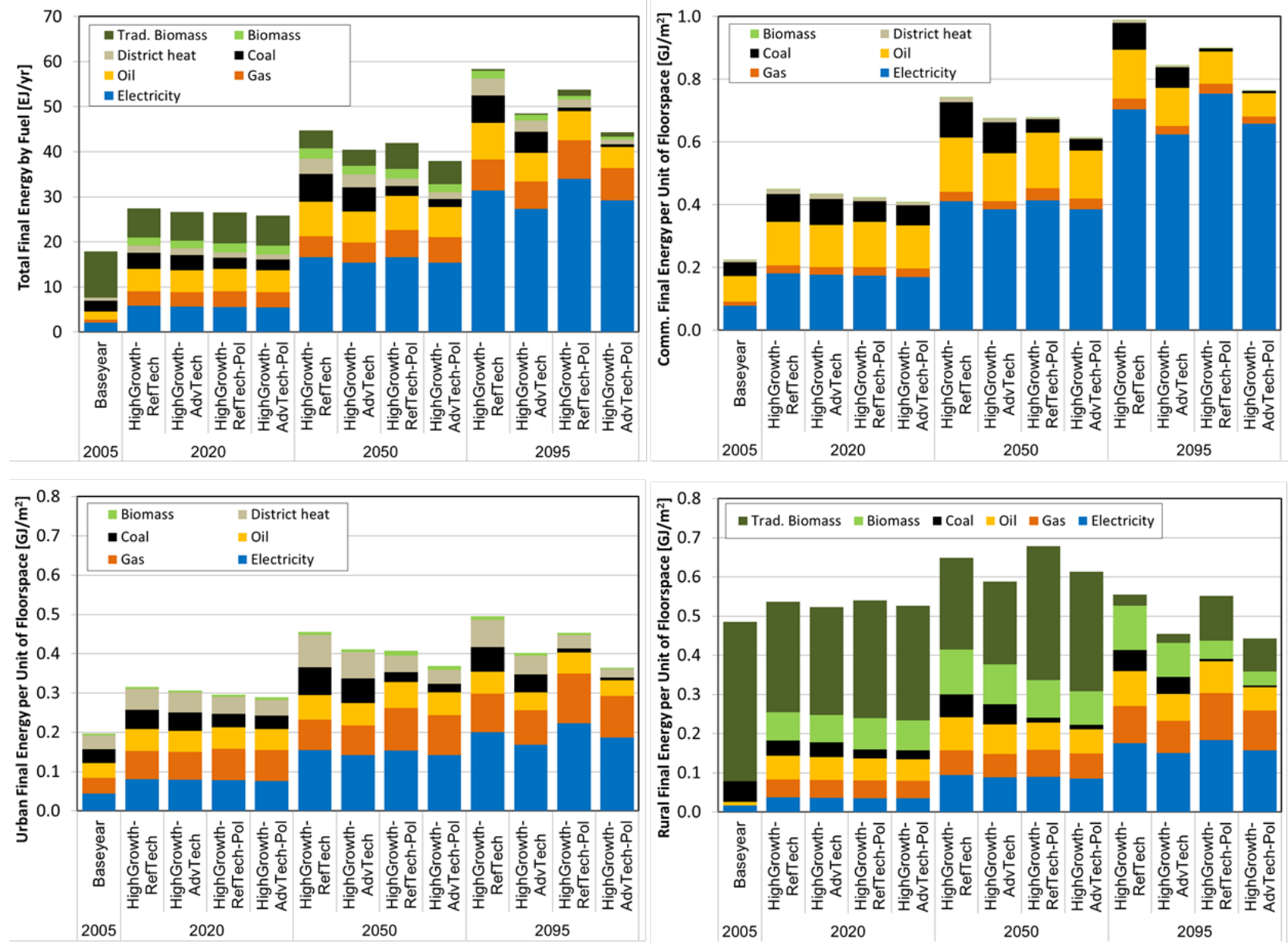

Figure 17: China buildings' total final energy consumption and energy uses per unit of floorspace for commercial, urban, and rural buildings
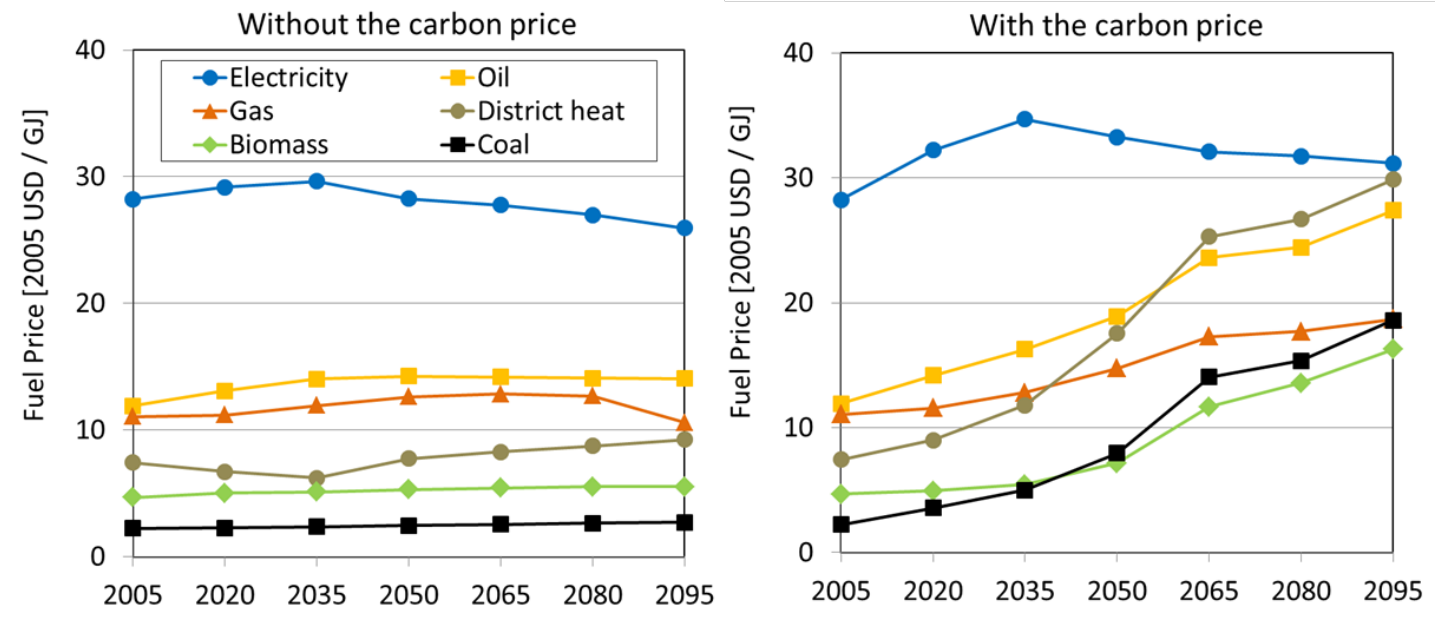

Figure 18: Prices of fuels delivered to the buildings sector (HighGrowth-RefTech scenarios) 
The second important point is that fuel switching and the growth in income lead to a continued and rapid electrification of the buildings sector throughout the century. The share of electricity in total final energy consumption nearly doubles by 2020 , eventually reaching $50-65 \%$ by 2095 across all scenarios (Figure 19). There are two reasons for this rapid electrification. One of the most important reasons is income-growth-driven expansion of electricity-delivered services such as cooling, lighting, appliances, and office equipment. This effect leads to the high-growth scenarios exhibiting more rapid electrification than the low-growth scenarios, regardless of technology assumptions and mitigation policy. Changes in fuel prices, with and without carbon policy, as well as improvements in important technologies such as electric heat pumps and electric water heaters also lead to electrification.
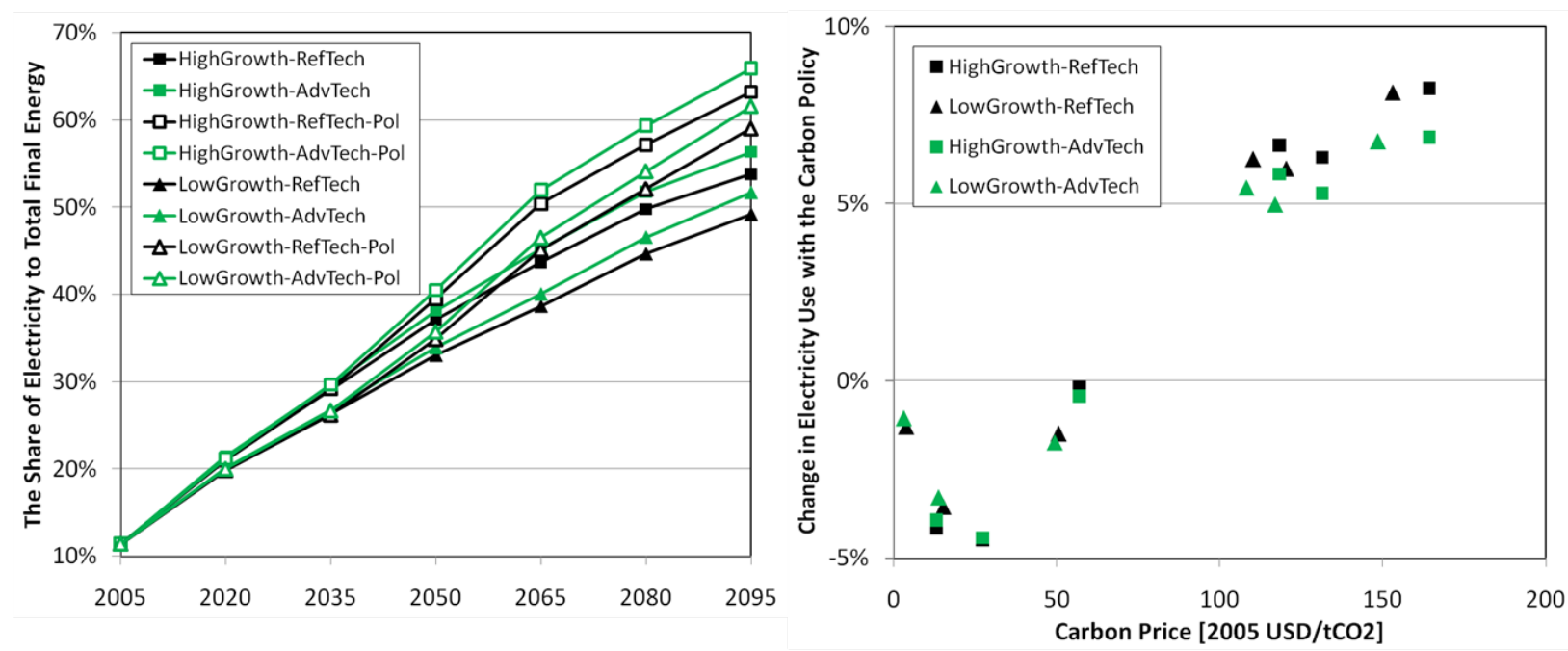

Figure 19: The share of electricity to total final energy consumption over time (left) and the percentage change in electricity consumption with the price on carbon (right) in the Chinese buildings sector

It is also instructive to take a closer look at the responsiveness of building electricity consumption to a price on carbon. Electrification under a carbon policy has long been a staple of large scale energy economic models. However, in virtually all cases, the degree of electrification has been arbitrarily imposed through parameters that define the elasticity of substitution at the aggregate scale. An obvious limitation of this approach is that without a structural model, these parameters may not have a meaningful basis, even if they are econometrically derived, particularly since they may change over time. Options for electrification in response to a price on carbon will depend on the service. For example, price-induced electrification in lighting, cooling, or plug loads is highly limited, because these services are already supplied almost exclusively with electricity. The options for price-induced electrification exist in services that rely predominantly on other end uses, such as heating, water heating, and cooking. The difficulty of 
electrification in these services is exacerbated over the long-term in countries like China with rapidly changing building energy systems. The potential for price-induced electrification today, on a relative basis, may be very different than in the future when plug loads and cooling have dramatically expanded as a portion of the total building energy demand. A structural model such as the one constructed here can represent these changes.

In this light, it is interesting to note that the price-induced electrification effects are only present well past mid-century, when carbon prices reach $\$ 100 / \mathrm{tCO}_{2}$ and above (Figure 19). Before then, the priceinduced electrification effects are dominated by the price-induced demand reduction in services that use electricity, so that, with the carbon price of around $\$ 60 / \mathrm{tCO}_{2}$ and below, de-electrification occurs in final energy consumption up to the level of $4 \%$. This is because the bulk of electrification occurs simply because of the income-driven growth in electricity-intensive services. It was found, however, that later in the century, carbon price at the level of \$110-160 induces about 5-8\% increase in electricity consumption. And the responsiveness to a carbon price is generally greater in the reference technology scenarios than in the advanced technology scenarios, where the faster decreases in the consumption of heating and cooling electricity due to the more rapid improvements in building envelope dominates the faster fuel shift toward electricity at the service level.

Finally, it is important to note the relationship between traditional biomass and district heating, on the one hand, and carbon policy on the other. The scenarios indicate that the application of a carbon policy may lead to a prolonged use of traditional biomass in rural residential buildings (Figure 12: Energy service per unit of floorspace in urban residential, rural residential, and commercial buildings with respect to China's per capita GDP during the century in the high-growth no-policy case.). The reason for this is that traditional biomass is assumed not to receive a price on carbon. If this were the case, it would become less expensive relative to other fuels as a result of the carbon policy, and this would prolong its use. This is an important point. Analysts have pointed out for years the importance of full sectoral coverage in carbon regimes. In developing countries, the use of traditional biomass may present special challenges in implementing effective carbon policy, just as it presents special challenges for other social and environmental priorities.

The carbon policy has the opposite effect on district heating. That is, district heating is reduced substantially in the carbon policy (Figure 17). This is because district heating is assumed to be supplied entirely from fossil fuels and because it is assumed that the option for CCS is not available in district heating. One might question the validity of both of these assumptions over time and under the imposition of strict carbon policy, which indicate a strong societal commitment to reduce $\mathrm{CO}_{2}$ emissions. At the very 
least, this result indicates that although district heat has some important advantages, it will also face some important challenges in the context of climate policy.

\subsection{Evolution of Building Service Demands and Fuel Uses in the Scenarios}

As noted above, long-term trends in final energy consumption and its characteristics, particularly for rapidly growing economies, are largely a result of developments in service demands. Developments in energy service demands are not uniform within and across the three Chinese building sectors; and their interaction with end-use energy efficiency gives distinctive pathways of fuel consumption. Technology improvement and mitigation policy also have important implications for building service demands and fuel uses at the sector level. Several salient points emerge from the energy service behavior of the scenarios.

Table 3: Development of building energy services ('WH\&C' stands for water heating and cooking)

\begin{tabular}{|c|c|c|c|c|c|c|c|c|c|c|c|}
\hline & \multirow{3}{*}{ Services } & \multirow{3}{*}{$\begin{array}{c}2005 \text { service } \\
\text { per unit of } \\
\text { floorspace } \\
{\left[\mathrm{GJ} \text {-out } / \mathrm{m}^{2}\right]}\end{array}$} & \multicolumn{9}{|c|}{ Percentage growth of service per unit of floorspace from 2005 numbers [\%] } \\
\hline & & & \multicolumn{3}{|c|}{ HighGrowth-RefTech } & \multicolumn{3}{|c|}{ HighGrowth-RefTech-Pol } & \multicolumn{3}{|c|}{ HighGrowth-AdvTech } \\
\hline & & & 2020 & 2050 & 2095 & 2020 & 2050 & 2095 & 2020 & 2050 & 2095 \\
\hline \multirow{5}{*}{ Urban } & Heating & 44.0 & 70 & 180 & 190 & 50 & 120 & 170 & 70 & 140 & 110 \\
\hline & Cooling & 26.7 & 100 & 290 & 360 & 90 & 270 & 360 & 90 & 240 & 240 \\
\hline & WH\&C & 49.8 & 50 & 60 & 60 & 40 & 60 & 60 & 50 & 60 & 60 \\
\hline & Lighting & 0.2 & 340 & 550 & 590 & 320 & 540 & 590 & 340 & 550 & 590 \\
\hline & Appliance & 21.8 & 110 & 360 & 590 & 110 & 350 & 590 & 110 & 370 & 590 \\
\hline \multirow{5}{*}{ Rural } & Heating & 33.4 & 150 & 320 & 290 & 150 & 300 & 290 & 140 & 260 & 180 \\
\hline & Cooling & 3.0 & 150 & 740 & 2430 & 140 & 680 & 2310 & 140 & 650 & 1820 \\
\hline & WH\&C & 72.8 & 10 & 10 & 10 & 10 & 10 & 10 & 10 & 10 & 10 \\
\hline & Lighting & 0.1 & 530 & 1440 & 1540 & 490 & 1420 & 1540 & 530 & 1440 & 1540 \\
\hline & Appliance & 8.2 & 150 & 710 & 1670 & 150 & 680 & 1660 & 160 & 720 & 1680 \\
\hline \multirow{5}{*}{ Comm. } & Heating & 85.6 & 80 & 100 & 70 & 70 & 100 & 70 & 70 & 70 & 20 \\
\hline & Cooling & 51.3 & 130 & 350 & 370 & 120 & 340 & 370 & 120 & 290 & 240 \\
\hline & WH\&C & 33.9 & 110 & 250 & 270 & 100 & 230 & 270 & 110 & 250 & 270 \\
\hline & Lighting & 0.5 & 340 & 1530 & 3170 & 310 & 1400 & 3080 & 340 & 1530 & 3170 \\
\hline & Equipment & 21.4 & 170 & 750 & 1980 & 160 & 720 & 1930 & 170 & 770 & 2020 \\
\hline
\end{tabular}

Perhaps the most fundamental trend in the scenarios is that the total demand for energy services per unit of floorspace increases substantially over the century, as would be expected in a rapidly growing 
economy with associated increases in per-household income. This trend dominates the influence of both technology and carbon policy. The major exceptions to this trend are water heating and cooking in both urban and rural residential settings, and heating in commercial setting. It is important to note that the remaining services - those with higher growth—are largely served by electricity. This asymmetric service growth is one of the primary reasons for the general electrification of the building sector over time.

At the same time, the overall intensification of building energy services does not necessarily translate into the intensification of final energy consumption in all cases. For example, on the one hand, and not surprisingly, energy services per unit of floorspace in rural residential buildings expand faster than urban residential and commercial energy services, except for water heating and cooking services (Table 3). On the other hand, the increase in energy services is accompanied by a substantial decrease in the use of highly inefficient traditional biomass as a fuel source. Traditional biomass is gradually replaced by more efficient commercial fuels such as commercial biomass, oil, gas, and electricity to fulfill the increased rural energy service demands. Taking these two countervailing factors together, rural final energy consumption per unit of floorspace remains nearly the same during the century (Figure 17).

It is also important to return again to the difference between the effect of policy and that of technology. In general, a price on carbon has an almost negligible effect on building energy services. There are several reasons for this behavior. One reason is that the price of services is more than just the fuel price. It also includes the price of equipment and operating and maintenance costs. These tend to dilute the effect of fuel prices on service prices. Another reason is that many of the services are provided by electricity, and electricity prices rise only modestly in a carbon policy (Figure 18) due to the technology options that are available to decarbonize the electricity sector, such as nuclear power, carbon capture and storage, and renewable energy. (Note that we will discuss this effect in more detail in Section 4.5). Finally, the service demand response to service prices is generally smaller than the response to the assumed rapid growth in income over the century. The impact of technology on services is also limited. Technology improvements reduce the costs of producing services and should therefore generally lead to an increase in service demands. However, the effect is relatively small in the scenarios explored here with the exception of heating and cooling services. Both heating and cooling services are defined taking into account the thermal characteristics of the building shell. The advanced technology scenarios assume improvements in shell characteristics, and these improvements necessarily lead to decreases in the need for heating and cooling. 


\section{5 $\mathrm{CO}_{2}$ Emissions and Policy Costs}

Ultimately, one of the major goals of improved building technologies is the reduction of $\mathrm{CO}_{2}$ emissions. These reductions are the primary goal of carbon policy. For a comprehensive analysis of $\mathrm{CO}_{2}$ emissions, it is important to account for not only direct uses of fossil fuels but also indirect emissions that take into account the fossil fuels burned to generate electricity for the buildings sector. Total $\mathrm{CO}_{2}$ emissions are the sum of the direct and indirect emissions.
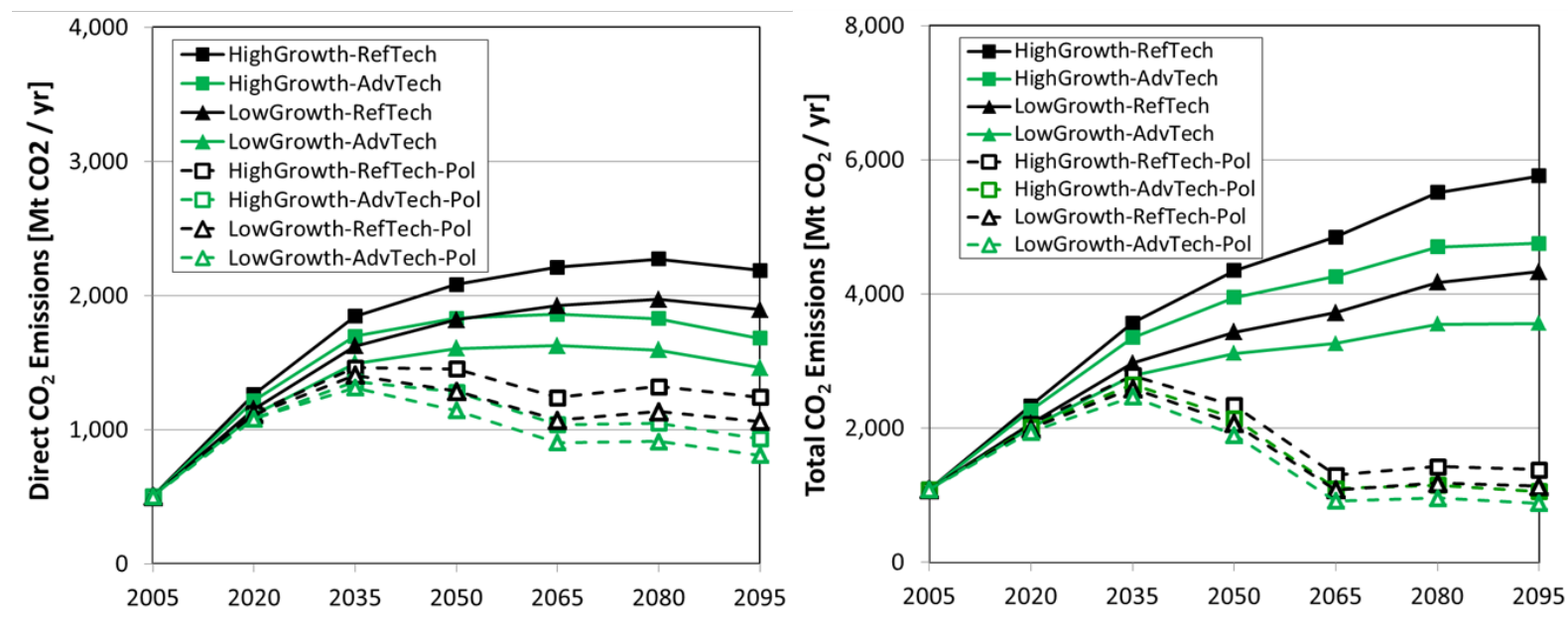

Figure 20: Direct and total $\mathrm{CO}_{2}$ emissions from the Chinese buildings sector

Not surprisingly, the carbon policy substantially reduces $\mathrm{CO}_{2}$ emissions from the buildings sector (Figure 20). Emissions begin to decline around the mid century under the policy assumed in this study. The emissions reduction is particularly significant in terms of total $\mathrm{CO}_{2}$ emissions because they represent the combined effect of the electrification of the buildings sector and the decarbonization of the power sector. Technology, in contrast, has a smaller effect on $\mathrm{CO}_{2}$ emissions than the carbon policy. As discussed in previous sections, the role of more efficient technologies is largely to reduce energy consumption and not to induce the sorts of fuel switching that are associated with a comprehensive carbon policy. Therefore, even in consideration of direct emissions, the effect of technology on $\mathrm{CO}_{2}$ emissions is smaller than that of the assumed policy. The difference is even larger when considering total $\mathrm{CO}_{2}$ emissions, because the technology solutions in the buildings sector have no influence on the character of electricity generation. The important point here is not that technology is not important, but simply that technology alone will not lead to the achievement of ambitious climate goals. It is also important to note that differences in economic growth, like technology, can influence total $\mathrm{CO}_{2}$ emissions without carbon 
policy, but they will not alone lead to the sorts of emissions pathways that are associated with stabilization.

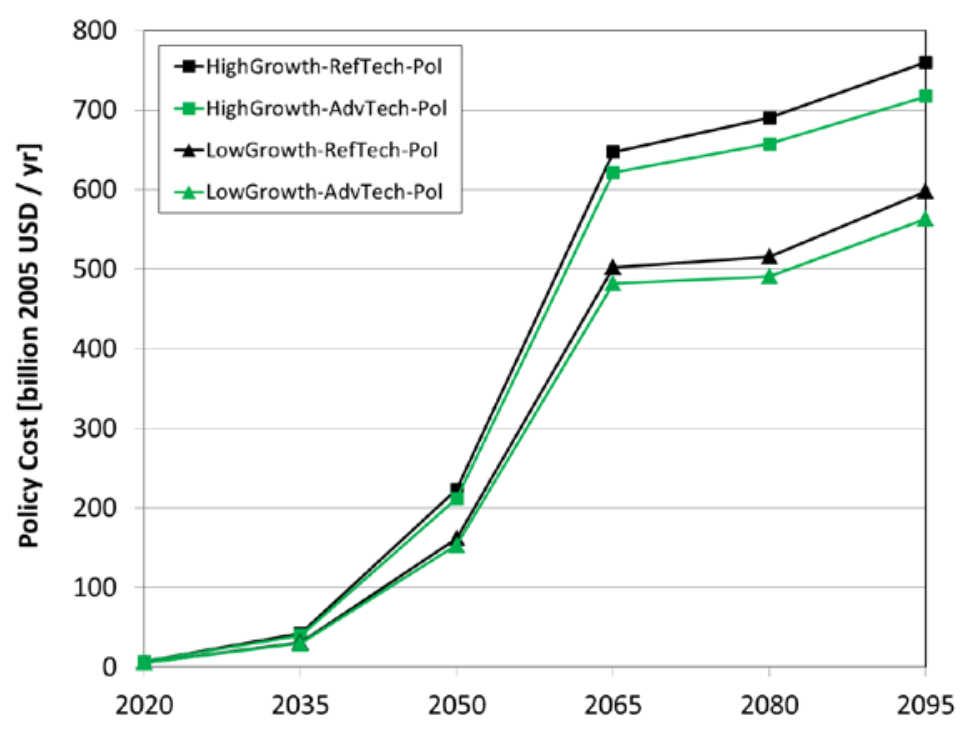

Figure 21: The costs of complying with the mitigation policy

Although technology will not by itself lead to stabilization, it can reduce the costs of meeting climate goals (Figure 21). ${ }^{15}$ The availability of advanced building technologies reduces the compliance costs by making emissions abatement easier than it would otherwise be. The higher is China's GDP growth, the greater the value (i.e., the gross reduction in the compliance costs) of implementing programs to promote advanced building technologies (Figure 21). Not surprisingly, the rate of economic growth also influences the costs of mitigation. Higher GDP increases costs because the demand for energy services and therefore carbon-emitting fuels increases with economic prosperity.

\footnotetext{
${ }^{15}$ The total cost of the carbon policy is computed as the changes in the sum of consumer surplus and producer surplus associated with the emissions reduction.
} 


\section{Conclusions and Policy Insights}

In this paper, we have presented a detailed, service-based model of China's building energy use, nested in the GCAM integrated assessment framework. Using the model, we have explored long-term pathways of China's building energy use and identified opportunities of reducing greenhouse gas emissions. The inclusion of a structural model of building energy demands within an integrated assessment framework represents a major methodological advance. It allows for a structural understanding of the drivers of building energy consumption while simultaneously considering the other human and natural system interactions that influence changes in the global energy system and climate.

In addition to methodological advances, the use of the model to create a range of different scenarios has provided insights into how China's building sector might evolve and what the implications might be for improved technology, regulatory policies such as building codes, and carbon policies. Perhaps the most fundamental result is that the analysis provided no reason to believe that China's building energy growth will wane anytime soon. Improvements to technology will put downward pressure on this growth, but will be insufficient to halt it. In this sense, the modeling simply confirms intuition. Beyond this general insight, the analysis has provided several more nuanced results.

First, the scenarios provide a sense of the tradeoffs between economy-wide carbon prices- $\mathrm{a}$ generalized, economy-wide carbon policy_and regulatory policies that would focus on building energy technology, for example through building codes and standards. Because carbon policy does not focus explicitly on energy consumption per se, it has less of an effect on energy consumption than technologybased policies might. On the other hand, carbon policy has a large effect on $\mathrm{CO}_{2}$ emissions from the buildings sector through increased electrification of the buildings sector along with decarbonization of electricity generation more generally in the economy. Policies focused explicitly on the deployment of higher efficiency technologies, in contrast, may have a more substantial influence on energy consumption, but they cannot lead to the necessary changes in fuel consumption patterns or decarbonization of electricity that are necessary to achieve long-term climate goals. The two means of addressing the buildings sector should be seen as complements in the context of climate mitigation in the sense that improved technologies can reduce the costs of meeting climate goals.

The analysis also provides insights into electrification of buildings in China. The analysis indicates that the rate of electrification - that is, the growth in the relative share of electricity in fuel consumption — of China's building sector will be well above that of developed regions. This is largely a result of the fact that China's buildings sector today demands relatively less of the services that rely predominantly on electricity (e.g., cooling, plug loads) than developed countries. These are precisely the 
sectors that will experience the most growth as China's economy develops. The fact that many Chinese live in rural environments today and many of these same Chinese are expected to move to the city is one of the primary drivers for this dynamic. In addition, the analysis provides an indication of the level of increased electrification that might emerge in response to carbon policy. This endogenous representation of this behavior is a major advantage of a structural model of building sector behavior. Non-structural models of the buildings sector, which are the norm for integrated assessment models, cannot endogenously capture this sort of behavior, and therefore may underestimate or overestimate its magnitude.

The analysis indicates that a continued expansion of district heating and combined heat and power (CHP) currently as planned by the Chinese government might help to reduce energy intensity of urban buildings and associated $\mathrm{CO}_{2}$ emissions in the near-term, but it could impose a major challenge in the context of long-term climate policy. The reason for this is that the expansion of district heating, which is largely based on fossil fuels, limits the options later for switching to electricity-based heating (e.g., electric heat pumps). Although this result largely emerges from the assumptions of the scenarios in this study, for example the assumption that CCS is not viable in district heating applications, it remains an important consideration in future planning.

Traditional biomass also provides a unique challenge, and one that is not present in developed economies. The scenarios indicate the importance of a transition away from traditional biomass in rural applications. Equally important, the scenarios point out the potential perverse effect that that traditional biomass consumption could increase under a climate policy. The reason for this is intuitive: traditional biomass, by assumption, will not be subject to a carbon price, whereas competing fuels will be subject to a carbon price and will therefore increase in price. This result points to the fact that traditional biomass will have to be treated largely independent of carbon policy.

Although the model presented in this paper represents a major methodological improvement, it is not without limitations. Here we highlight two of what we consider to be important areas for future research. First, although a major advance in the modeling of buildings in integrated assessment, it remains at a very aggregate level of detail. All of China is represented with only three sectors. Down-scaling the buildings sector, for instance, into several distinct climate regions exhibiting different energy use profiles, as well as different population and income pathways, would offer more robust and realistic insights into the effects of general climate policy instruments and region-specific measures. Second, the current analysis has not explored the implications that climate change may have for heating and cooling demands. Although the model is constructed to incorporate these effects, the capability was not exercised in this analysis. In the future, heating and cooling service demands could be coupled with climate change 
feedback to answer the questions of what climate change may imply for Chinese building energy consumption and how its fuel mix may shift accordingly. 


\section{References}

[1] IEA, Energy Balances of OECD/non-OECD Countries, 2007.

[2] CEG, China Energy Databook v7.0. China Energy Group, 2008.

[3] J. Li, Towards a Low-Carbon Future in China's Building Sector - A Review of Energy and Climate Models Forecast. Energy Policy 36(5) (2008) 1736-1747.

[4] P. Kyle, L. Clarke, F. Rong, S. Smith, Climate Policy and the Long-Term Evolution of the U.S. Building Sector. The Energy Journal 31(3) (2010) 131-158.

[5] L. Clarke, J. Edmonds, H. Jacoby, H. Pitcher, J. Reilly, R. Richels, Scenarios of Greenhouse Gas Emissions and Atmospheric Concentrations, U.S. Department of Energy, Office of Biological \& Environmental Research, Washington D.C., 2007.

[6] L. Clarke, M. Wise, J. Edmonds, M. Placet, P. Kyle, K. Calvin, $\mathrm{CO}_{2}$ Emissions Mitigation and Technological Advance: An Updated Analysis of Advanced Technology Scenarios, Pacific Northwest National Laboratory, WA, 2008.

[7] CSY, China Statistical Yearbook. National Bureau of Statistics of China, Beijing, 2009.

[8] A. Bauen, M. Kaltschmitt, Reduction of Energy-Related CO2 Emissions. 1st World Conference on Biomass for Energy and Industry, Spain, 2000, p.1354.

[9] J. Sinton, Accuracy and Reliability of China's Energy Statistics, Lawrence Berkeley National Laboratory, CA, 2001.

[10] N. Zhou, M. McNeil, D. Fridley, J. Lin, L. Price, S. Can, Energy Use in China: Sectoral Trends and Future Outlook. Lawrence Berkeley National Laboratory, CA, 2007.

[11] N. Zhou, J. Lin, The Reaility and Future Scenarios of Commercial Building Energy Consumption in China. Energy and Buildings 40 (2008) 2121-2127.

[12] Y. Tonooka, H. Mu, Y. Ning, Y. Kondo, Energy Consumption in Residential House and Emissions Inventory of GHGs, Air Pollutants in China, Journal of Asian Architecture and Building Engineering 2 (2003) 93-100.

[13] D. Brockett, D. Fridley, J. Lin, J. Lin, A Tale of Five Cities: The China Residential Energy Consumption Survey, Proceedings of the 2002 American Council for An Energy-Efficient Economy's Summer Study on Energy Efficiency in Buildings, 2002, p.12. 
[14] A. Meyer, K. Kalkum, China: Development of National Heat Pricing and Billing Policy. Energy Sector Management Assistance Program, The World Bank Group, 2008.

[15] Odyssee, Database for Energy Efficiency Indicators in Europe, http://www.odyssee-indicators.org/, 2009.

[16] USBED, US Building Energy Data Book, 2009.

[17] X. Hu, K. Jiang, Evaluation of Technology and Countermeasure for Greenhouse Gas Mitigation in China. Publishing House of China's Environmental Science, Beijing, 2001.

[18] WEO, World Energy Outlook 2007: China and India Insights, 2007.

[19] ERI, China's Sustainable Energy Future, Energy Research Institute, Beijing, China, 2003.

[20] EIA, International Energy Outlook, Department of Energy, Washington, DC, USA, 2006.

[21] J. Edmonds, J. Clarke, J. Dooley, S. Kim, S. Smith, Stabilization of $\mathrm{CO}_{2}$ in a B2 World: Insights on the Roles of Carbon Capture and Disposal, Hydrogen, and Transportation Technologies, Energy Economics 26(4) (2004) 517-537.

[22] S. Kim, J. Edmonds, J. Lurz, S. Smith, M. Wise, The ObjECTS Framework for Integrated Assessment: Hybrid Modeling of Transporation. Energy Journal 27 (2006) 63-91.

[23] N. Nakicenovic, J. Alcamo, G. Davis, B. Vries, J. Fenhann, S. Gan, Special Report on Emissions Scenarios. Cambridge University Press, 2000.

[24] J. Edmonds, J. Reilly, Global Energy: Assessing the Future, Oxford University Press, Oxford, U.K., 1985.

[25] R. Sands, M. Leimbach, Modeling Agriculture and Land Use in an Integrated Assessment Framework. Climatic Change 56 (1) (2003) 185-210.

[26] T. Wigley, S. Raper, Reasons for Larger Warming Projections in the IPCC Third Assessment Report. Journal of Climate 15(20) (2002) 2945-2952.

[27] J. Clarke, J. Edmonds, Modeling Energy Technologies in a Competitive Market. Energy Economics, April (1993) 123-129.

[28] D. McFadden, Econometric Models for Probabilistic Choice Among Products. The Journal of Business 53 (3) (1980) S13-S29.

[29] K. Train, Qualitative Choice Analysis: Theory, Econometrics, and an Application to Automobile Demand. MIT Press, 1993. 
[30] L. Zhang, S. Zhao, Re-examining China’s 'urban' concept and level of urbanization, The China Quarterly 154 (1998) 330-381.

[31] NAP, Urban Population Dynamics: Models, Measures, and Forecasts, in: Cities

Transformed:Demographic Change and Its Implications in the Developing World, The National Academies Press, 2003.

[32] K. Chan, Y. Hu, Urbanization in China in 1990s: New Definition, Different Series, and Revised Trends. The China Review , 3(2) (2003) 49-71.

[33] K. Zhang, S. Song, Rural-urban Migration and Urbanization in China: Evidence from Time-series and Corss-section Analyses. China Economic Review 14 (2003) 386-400.

[34] M. Todaro, A Model of Laobr, Migration, and Urban Unemployment in Less Developed Countries. American Economic Review 59 (1969) 138-148.

[35] D. Jorgenson, The Development of A Dual Economy. Economic Journal 71 (1961) 309-334.

[36] J. Harris, M. Todaro, Migration, Unemployment, and Development: A Two-sector Analysis. American Economic Review 60 (1970) 126-142.

[37] WDI, World Development Indicators, 2011.

[38] UNPD, World Urbanization Prospects. UN Population Division, 2009.

[39] A. Grubler, B. O'Neill, K. Riahi, V. Chirkov, A. Goujon, P. Kolp, Regional, National, and Spatially Explicit Scenarios ofo Demographic and Economic Chnage based on SRES, Technological Forecasting and Social Change 74 (2007) 980-1029.

[40] D. Vuuren, P. Lucas, H. Hilderink, Downscaling Drivers of Global Environmental Change: Enabling Use of Global SRES Scenarios at the National and Grid Levels. Global Environmental Change 17 (2007), 114-130.

[41] G. Chow, L. Niu, Demand and Supply for Residential Housing in Urban China, in: J. Man (Eds.), China's Housing Reform and Outcomes, Lincoln Institute Press, MA, 2010.

[42] OECD, Statistics Portal, OECD, http://www.oecd.org/statsportal, 2011.

[43] J. Anderson, J. Kushman, A Model of Household Heating Demand: Home Production with Satiety and an Endowment, The Journal of Consumer Affairs 21(1) (1987) 1-20.

[44] A. Henley, J. Peirson, Non-linearities in Electricity Demand and Temperature: Parametric Versus Non-parametric Methods, Oxford Bulletin of Economics and Statistics 59 (1) (1997) 149-162. 
[45] C. Guertin, S. Kumbhakar, A. Duraiappah, Determining Demand for Energy Services: Investigating Income-Driven Behaviours, International Institute for Sustainable Development, 2003.

[46] E. Larson, W. Zongxin, P. DeLaquil, C. Wenying, G. Pengfei, Future Implications of China's Energy-Technology Choices. Energy Policy 31 (2003) 1189-1204.

[47] M. Evans, B. Shui, A. Delgado, Shaping the Energy Efficiency in New Buildings. Pacific Northwest National Laboratory, WA, 2009.

[48] J. Edmonds, T. Wilson, M. Wise, J. Weyant, Electrification of the Economy and $\mathrm{CO}_{2}$ Emissions Mitigation, Environmental Economics and Policy Studies 7 (2006) 175-203. 


\section{Appendix 1: Technology Assumptions in the Scenarios}

Table A1. Assumptions for technology efficiencies in residential buildings

\begin{tabular}{|c|c|c|c|c|c|c|c|}
\hline \multirow{2}{*}{ Energy service } & \multirow{2}{*}{ Technology } & \multirow{2}{*}{ Unit } & & \multicolumn{2}{|c|}{ Ref Tech } & \multicolumn{2}{|c|}{ Adv Tech } \\
\hline & & & 2005 & 2050 & 2095 & 2050 & 2095 \\
\hline \multirow{2}{*}{$\begin{array}{l}\text { Urban building } \\
\text { Rural building }\end{array}$} & Building shell & $\mathrm{W} / \mathrm{m}^{2} \mathrm{~K}$ & 1.7 & 1.5 & 1.3 & 1.3 & 0.9 \\
\hline & Building shell & $\mathrm{W} / \mathrm{m}^{2} \mathrm{~K}$ & 2.0 & 1.7 & 1.5 & 1.5 & 1.1 \\
\hline \multirow{7}{*}{ Heating } & Coal furnace & output/input & 0.50 & 0.52 & 0.55 & \multirow{7}{*}{\multicolumn{2}{|c|}{$\begin{array}{l}\text { Same as Ref Tech } \\
\text { Same as Ref Tech } \\
2.46 \quad 2.75 \\
\text { Same as Ref Tech } \\
\text { Same as Ref Tech } \\
\text { Same as Ref Tech } \\
0.85 \quad 0.95\end{array}$}} \\
\hline & Electric furnace & output/input & 0.92 & 0.96 & 1.00 & & \\
\hline & Electric heat pump & output/input & 2.20 & 2.30 & 2.41 & & \\
\hline & Trad. biomass furnace $\dagger$ & output/input & 0.20 & 0.21 & 0.22 & & \\
\hline & Comm. biomass furnace $\dagger$ & output/input & 0.40 & 0.42 & 0.44 & & \\
\hline & Oil furnace & output/input & 0.70 & 0.73 & 0.77 & & \\
\hline & Gas furnace & output/input & 0.76 & 0.80 & 0.83 & & \\
\hline Cooling & Air conditioning & output/input & 2.93 & 3.28 & 3.67 & 3.67 & 4.59 \\
\hline \multirow{6}{*}{$\begin{array}{l}\text { Water Heating } \\
\& \text { Cooking } \\
(\mathrm{WH} \& \mathrm{C})\end{array}$} & Coal WH\&C & output/input & 0.40 & 0.42 & 0.44 & \multirow{6}{*}{\multicolumn{2}{|c|}{$\begin{array}{l}\text { Same as Ref Tech } \\
0.90 \quad 1.00 \\
\text { Same as Ref Tech } \\
0.56 \quad 0.63 \\
\text { Same as Ref Tech } \\
\text { Same as Ref Tech }\end{array}$}} \\
\hline & Electric WH\&C & output/input & 0.80 & 0.84 & 0.88 & & \\
\hline & Oil WH\&C & output/input & 0.50 & 0.52 & 0.55 & & \\
\hline & Gas WH\&C & output/input & 0.50 & 0.52 & 0.55 & & \\
\hline & Trad. biomass $\mathrm{WH} \& \mathrm{C} \dagger$ & output/input & 0.20 & 0.21 & 0.22 & & \\
\hline & Comm. biomass $\mathrm{WH} \& \mathrm{C} \dagger$ & output/input & 0.40 & 0.42 & 0.44 & & \\
\hline \multirow{4}{*}{ Lighting } & Incandescent lighting & lumens/W & 14 & 15 & 16 & \multirow{4}{*}{\multicolumn{2}{|c|}{$\begin{array}{l}\text { Same as Ref Tech } \\
\text { Same as Ref Tech } \\
131 \\
\text { Same as Ref Tech }\end{array}$}} \\
\hline & Fluorescent lighting & lumens/W & 82 & 86 & 90 & & \\
\hline & Solid state lighting & lumens/W & 105 & 117 & 131 & & \\
\hline & Oil lamp $\dagger$ & lumens/liter & 1,250 & 1,300 & 1,350 & & \\
\hline Appliance & Electric appliances & output/input & 1.00 & 1.05 & 1.09 & 1.12 & 1.25 \\
\hline
\end{tabular}

$\dagger$ These technologies are used only in rural residential buildings. 
Table A2. Assumptions for technology efficiencies in commercial buildings

\begin{tabular}{|c|c|c|c|c|c|c|c|}
\hline \multirow{2}{*}{ Energy service } & \multirow{2}{*}{ Technology } & \multirow{2}{*}{ Unit } & & \multicolumn{2}{|c|}{ Ref Tech } & \multicolumn{2}{|c|}{ Adv Tech } \\
\hline & & & 2005 & 2050 & 2095 & 2050 & 2095 \\
\hline Comm. Building & Building shell & $\mathrm{W} / \mathrm{m}^{2} \mathrm{~K}$ & 1.5 & 1.3 & 1.1 & 1.1 & 0.8 \\
\hline \multirow{6}{*}{ Heating } & Coal furnace & output/input & 0.65 & 0.68 & 0.71 & \multirow{2}{*}{\multicolumn{2}{|c|}{$\begin{array}{l}\text { Same as Ref Tech } \\
\text { Same as Ref Tech }\end{array}$}} \\
\hline & Electric furnace & output/input & 0.92 & 0.96 & 1.00 & & \\
\hline & Electric heat pump & output/input & 2.50 & 2.62 & 2.74 & 2.80 & 3.13 \\
\hline & Comm. biomass furnace & output/input & 0.40 & 0.42 & 0.44 & Same & ef Tech \\
\hline & Oil furnace & output/input & 0.70 & 0.73 & 0.77 & Same & ef Tech \\
\hline & Gas furnace & output/input & 0.76 & 0.80 & 0.83 & 0.85 & 0.95 \\
\hline \multirow{2}{*}{ Cooling } & Electric AC & output/input & 2.93 & 3.28 & 3.67 & 3.67 & 4.59 \\
\hline & Gas AC & output/input & 2.34 & 2.62 & 2.94 & 2.93 & 3.67 \\
\hline \multirow{4}{*}{$\begin{array}{l}\text { Water Heating } \\
\text { \& Cooking } \\
(\mathrm{WH} \& \mathrm{C})\end{array}$} & Coal WH\&C & output/input & 0.50 & 0.52 & 0.55 & \multirow{4}{*}{\multicolumn{2}{|c|}{$\begin{array}{l}\text { Same as Ref Tech } \\
0.90 \quad 1.00 \\
\text { Same as Ref Tech } \\
0.67 \quad 0.75\end{array}$}} \\
\hline & Electric WH\&C & output/input & 0.80 & 0.84 & 0.88 & & \\
\hline & Oil WH\&C & output/input & 0.50 & 0.52 & 0.55 & & \\
\hline & Gas WH\&C & output/input & 0.60 & 0.63 & 0.66 & & \\
\hline \multirow{3}{*}{ Lighting } & Incandescent lighting & lumens/W & 14 & 15 & 16 & \multirow{2}{*}{\multicolumn{2}{|c|}{$\begin{array}{l}\text { Same as Ref Tech } \\
\text { Same as Ref Tech }\end{array}$}} \\
\hline & Fluorescent lighting & lumens/W & 82 & 86 & 90 & & \\
\hline & Solid state lighting & lumens/W & 105 & 117 & 131 & 131 & 165 \\
\hline Equipment & Electric equipment & output/input & 1.00 & 1.05 & 1.09 & 1.12 & 1.25 \\
\hline
\end{tabular}




\section{Appendix 2: Theoretical Overview of Demand Satiation}

This section briefly discusses about the approach we have taken to represent the behavior of demand satiation as expressed by energy service delivered per unit of floorspace. The idea is that, given that an energy service has its own satiation point, consumers chooses an efficient demand for the service, considering their income and the service cost, which changes over time as fuel price and technology evolve. The core model parameter, the saturation impedance, represents how important each energy service is to the consumers relative to other energy services. This approach allows modelers to differentiate the rate of expansion of energy services within and across the building sectors.

Figure 22 schematically illustrates how building energy service demand $d_{j}$ changes with shifting income and prices in the presence of the demand's satiation, $\bar{q}_{j}$, where $j \in\{A, B\}$. The left figures show iso-utility curves for a representative consumer, on which he/she balances the consumption of energy service $d_{j}$ and other composite goods $d_{X}$, given their relative prices $P_{X} / P_{j}$ and income $i$; and the right figures show the resulting efficient demand trajectories for $d_{j}$ with changes in $i$ and $P_{j}$. Note that the utility curves exhibit the behavior of satiation for $q_{j}$ : Below $\bar{q}_{j}$, the consumer becomes increasingly better off by consuming more of $d_{j}$, whereas, above $\bar{q}_{j}$, the consumer becomes increasingly worse off.

To contrast the effects of preferences held by the consumer over different energy services, the same set of figures are made for two different types of energy services, denoted as Services $A$ and $B$; compared to $B, A$ is the more necessary service because the same decline in the demand $d_{j}$ must be compensated for by a greater increase in $d_{X}$ to maintain the same level of utility. The right figures indicate that as income grows, both $d_{A}$ and $d_{B}$ increase with decreasing rates, approaching the asymptotes of $\bar{q}_{A}$ and $\bar{q}_{B}$, respectively. Two points are worth making. First, given income trajectories, the rate of demand saturation is greater when the price of energy service is lower. Second, given income and service price, the rate of demand saturation is greater when the service is more necessary-or, equivalently, the service's saturation impedance is lower. The satiated demand model used in this study captures these important behaviors (Eq. 8).

Of course, this model has several limitations. First, the expansion of energy services implied by the model may not necessarily fulfill the constraint that the consumers might appropriate for their total energy expenses. Second, like Cobb-Douglas demand model, the satiated demand model has homogeneous degree zero in price and income (Eq. 8). That is, for example, although price doubles, as long as income doubles at the same time, demand would remain the same. To avoid these limitations, one might think of slightly modifying the model or introducing additional parameters. Yet, in the absence of 
extensive empirical data for energy consumption particularly in the service level, we did not explore this issue more in depth.

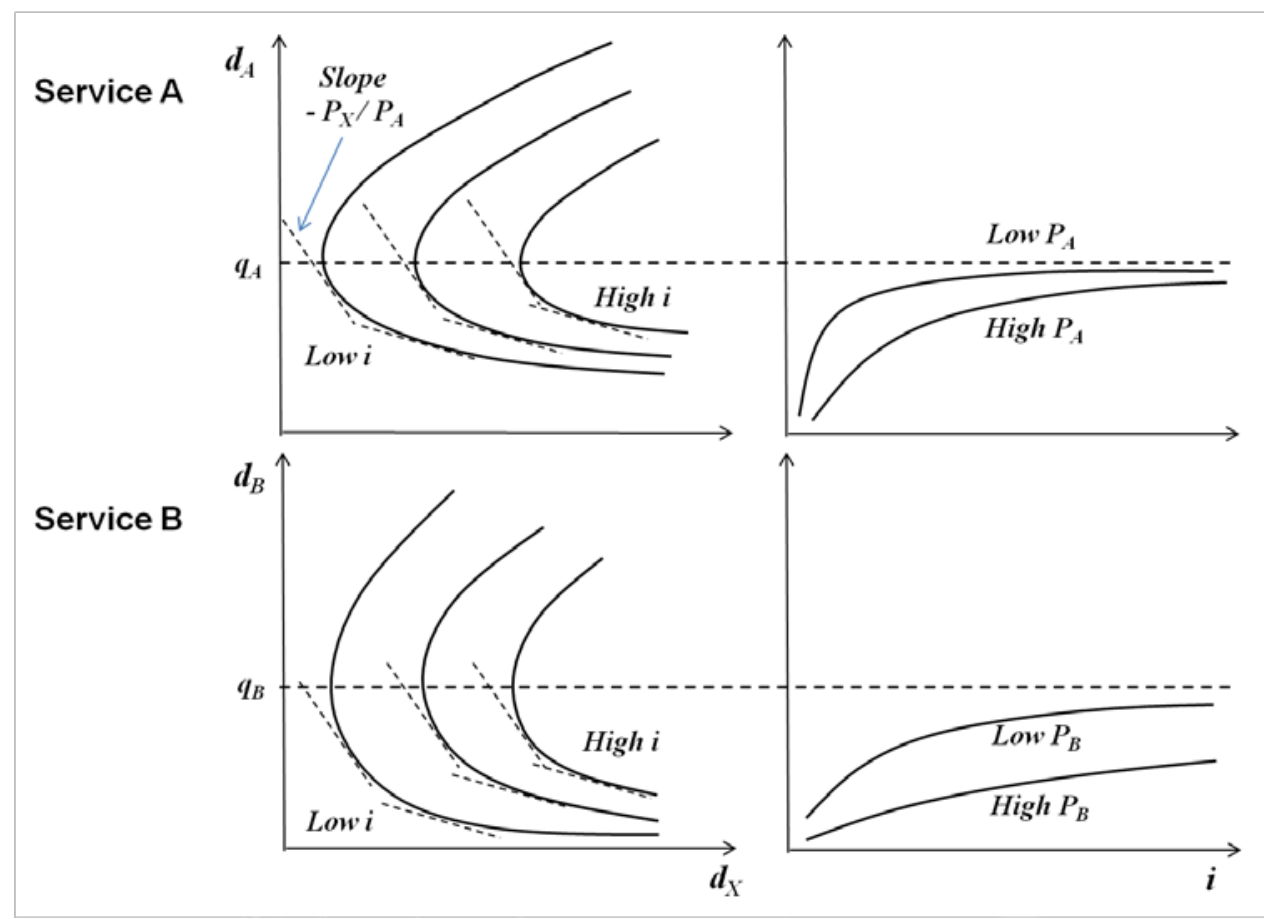

Figure 22: A schematic illustration of the choice of building service demand 